\title{
Research \\ Policy Research Using Agent-Based Modeling to Assess Future Impacts of Urban Expansion into Farmlands and Forests
}

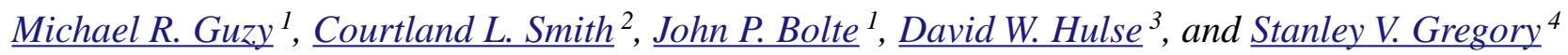

\begin{abstract}
The expansion of urban land uses into farmlands and forests requires an assessment of future ecological impacts. Spatially explicit agent-based models can represent the changes in resilience and ecological services that result from different land-use policies. When modeling complex adaptive systems, both the methods used to interpret results and the standards of rigor used to judge adequacy are complicated and require additional research. Recent studies suggest that it would be appropriate to use these models as an extension of exploratory analysis. This type of analysis generates ensembles of alternate plausible representations of future system conditions. User expertise steers interactive, stepwise system exploration toward inductive reasoning about potential changes to the system. In this study, we develop understanding of the potential alternative futures for a social-ecological system by way of successive simulations that test variations in the types and numbers of policies. The model addresses the agriculturalurban interface and the preservation of ecosystem services. The landscape analyzed is at the junction of the McKenzie and Willamette Rivers adjacent to the cities of Eugene and Springfield in Lane County, Oregon. Our exploration of alternative future scenarios suggests that policies that constrain urban growth and create incentives for farming and forest enterprises to preserve and enhance habitat can protect ecosystem resilience and services.
\end{abstract}

Key Words: social-ecological systems; agricultural-urban interface; fish habitat; ecosystem health; urban containment policies; agent-based models

\section{INTRODUCTION}

Worldwide, urban systems are expanding into lands that are valuable for agricultural and forest production and impinging on the health and resilience of social-ecological systems (SES). These land-use changes produce current benefits at the cost of eliminating future options for ecosystem goods and services (Farber et al. 2006). Population growth drives the evolution of urban systems and the objectives of many land management decisions. Over the course of time, the affected processes interact to yield complex disturbances, unanticipated events (Allen and Lu 2003, Ricketts and Imhoff 2003), and economic and ecological scarcities (Langridge et al. 2006). To develop a societal ethic that sustains biodiversity and other aspects of longterm ecological resilience (sensu Levin 1998), it is important to study the consequences of land-use policies and decisions that affect the dynamics of social-ecological systems (Tilman 2000, Perrings 2006).
Land-use policy research requires new tools to investigate complex SES and the human and natural feedbacks in these systems. Some of the desired features of these tools include a spatially explicit representation of the landscape, agent-based behaviors, indicators of ecological and social change, and the capacity to explore alternate futures and incorporate detailed biophysical and social processes. Providing and using these new tools is challenging because of the demands for empirical realism and complexity (Janssen and Ostrom 2006). Furthermore, using these tools to gain understanding in an alternate futures application, such as the SES case study we present here, requires a method that can withstand the criticism that the future cannot be predicted. To address these issues, we present a case study that describes both a new land-use policy research methodology and a tool that models the dynamics of human and natural processes at the tributary junction of a large river.

The tool we use is intended mainly for policy research. It provides a means to translate real-world

\footnotetext{
${ }^{1}$ Oregon State University, Department of Biological and Ecological Engineering, ${ }^{2}$ Oregon State University, Department of Anthropology, ${ }^{3}$ University of Oregon, Department of Landscape Architecture, ${ }^{4}$ Oregon State University, Department of Fisheries and Wildlife
} 
policies into an agent-based model. By policy, we mean land management options that span the domains of zoning, agricultural and forest production, environmental protection, and urban development, including the associated regulations, laws, and practices. The policies we used in our SES simulations include urban containment policies (Bengston and Youn 2006). Two policies of this type governing urban growth boundaries (UGB) and urban service boundaries constrain urban sprawl in the United States. The first UGB policy in the United States was established in 1958 in Fayette County, Kentucky (Kolakowski et al. 2000:2). Statewide UGB policies were a 1973 Oregon innovation.

We also used policies modeled on agricultural practices that affect ecosystem services and capital (Tilman et al. 2002). In our study area and elsewhere, agricultural enterprises are beginning to be rewarded for providing habitat for valued ecosystem services such as water quality improvement, fish and wildlife habitat, and protection for endangered species, wetlands, and biodiversity. Reward-based programs in Europe and the United States are intended to address the loss of ecosystem functions on agricultural lands. In Europe in the late 1990s, these "agri-environment schemes" were applied to $20 \%$ of European Union farmlands at an annual cost of $€ 2.2$ billion (U.S. $\$ 2.6$ billion in 2003 dollars) for 2000-2003 (Herzog 2005:176). For annual payments of U.S. $\$ 1.7$ billion ( $€ 1.2$ billion), the United States had 13 million ha under contract (FSA 2006) in the Conservation Reserve Program and the smaller Conservation Reserve Enhancement Program. The Natural Resources Conservation Service allocated another U.S. \$1.5 billion in 2005 (NRCS 2006) for the Environmental Quality Incentives Program, Farm and Ranch Lands Protection Program, Grassland Reserve Program, Wetlands Reserve Program, and Wildlife Habitat Incentives Program. An additional 1667 land trusts give tax advantages for designating land for conservation purposes. By 2005, these land trusts protected 15 million ha (Land Trust Alliance 2005).

We used our policy tool to explore how policy can be made to work toward a future characterized by optimal ecosystem health and economic value. In an analysis that links the resilience and stability of biophysical systems with the economic activities within those systems, Common and Perrings (1992) found that the goal of ecological stability (sensu Holling) requires intervention mediated by human values or ethics and does not result from an efficient rational market alone. To represent this human dimension, our policy research tool predicates policy choice upon individual preferences. These preferences are represented in our tool by agentbased modeling (ABM), which is recognized as a way to compute and include knowledge about social actors and systems (Bankes et al. 2002, Janssen and Ostrom 2006). In the typology of Klügl et al. (2004), our tool dynamically generates behavior rather than describing agent behavior by a priori routines. The tool's mechanism generates agent behavior as a sequence of policy choices biased by agent preferences such that the intentions of selected policies are likely to match agent preferences for ecosystem health vs. economic goals. Policy intentions quantify the expected effect of the policy on ecosystem health and economic values. These intentions, also called efficacies in the vernacular of the tool, are assigned by expert knowledge or may be estimated using the tool itself. The tool uses simple agents, each of which is bound to a specific parcel of land, in a construct not dissimilar to other spatially explicit models that characterize agents by one or a few attributes, e.g., a preference for living next to someone like oneself, and simple rules describing behavior in response to spatial context (Schelling 1971, Janssen and Ostrom 2006). Simpler agents are commonly found in hybrid tools that also model environmental effects and processes that are not inherently agent-based (Bankes et al. 2002). The issue of the complexity of agent representation in $\mathrm{ABM}$ is discussed by many authors (e.g., Parker et al. 2003, Benenson and Torrens 2004). Table 1 summarizes the range of agent complexity and is an extension of that published by Benenson and Torrens (2004:156).

A review of multi-agent system models and land use and cover change (Parker et al. 2003) noted the obstacles to empirical agent parameterization and the lack of social data at a suitable scale (Evans and Kelley 2004). Recent work has shown the significant effect on outcomes of incorporating empirically sampled heterogeneity into the simulated set of agents (Brown and Robinson 2006). That work and others (Berger and Schreinemachers 2006) used survey instruments to sample real populations and various techniques for injecting empirical information into a spatially explicit ABM. Appendix 1 summarizes (1) the representations of agents in our tool, which are derived from validated empirical, approaches used to determine peoples' values using demographic data (Van Liere and 
Table 1. Characteristics of agents in Evoland compared to a comprehensive list modified from a table by Benenson and Torrens (2004:156). The temporal distribution of agent decisions in Evoland approximates a Poisson process with user-specified mean frequency (10 yr for the case study).

\begin{tabular}{lll}
\hline \hline Property & Meaning & Evoland \\
\hline Reactive & Responds to environment & Yes \\
Autonomous & Controls own actions & Yes \\
Flexible & Actions not scripted & Yes \\
Goal-oriented & More than responsive to environment & Yes \\
Temporally continuous & Agent behavior continuous & No (Poisson) \\
Interactive physically & Individual decisions affect other actors & Yes \\
Interactive socially & Interact as groups of actors to affect others & No \\
Communicative & Communicates with other agents & No \\
Mobile & Can transport self to other locations & No \\
Learning & Changes based on experience & No \\
Character & Believable personality or emotions & No \\
\hline
\end{tabular}

Dunlap 1980, Dietz et al. 1998, Vaske et al 2001, Steel et al. 2003) and (2) the location and number of votes cast on environmental ballot measures that reflect land-use actions that the people voting are willing to take (Deacon and Shapiro 1975, Kahn and Matsusaka 1997, Salka 2003, Vossler and Kerkvliet 2003, Vossler et al. 2003).

The tool includes submodels that dynamically evaluate landscape performance with respect to ecosystem health and economic value. It optimizes these dynamic values sequentially in time and space via the mechanism of agent-based policy choice. When the landscape performance for these goals is deficient, the tool dampens the effect of individual preferences and is likely to select policies that reverse the deficiency, even if individual preferences do not match the policy intention. To facilitate evaluations of fish biodiversity and abundance, vegetative succession, and other processes critical to ecosystem resilience, the tool embeds a simple space-time geographic information system that supports environmental effects and processes not inherently agent-based. This feature increases the capacity of the tool for complex analyses (Brown et al. 2005). The tool includes features of advanced ABM that permit landscape change and agent decision making to occur simultaneously (Graniero and Robinson 2006) in a tight coupling, including identity, causal, temporal, and topological relationships between agents and the landscape (Brown et al. 2005).

\section{METHODS AND THE EVOLAND MODELING PLATFORM}

The tool we used is called Evoland 3.5. We describe it using the Grimm et al. (2006) protocol for describing individual- and agent-based models. The protocol consists of seven elements. The first three elements provide an overview of the tool's purpose, state variables and scales, and process and scheduling. The fourth element explains general concepts underlying the model's design, and the remaining three elements provide details on initialization, input, and submodels. The major features of Evoland 3.5 are described in Appendices 
1-8. Complete source code, input files, and more detailed technical documentation are available on the Web site at http://evoland.bioe.orst.edu/.

\section{Purpose}

The Evoland modeling approach is summarized by Bolte et al. (2007) in terms of the challenges of and recent trends in modeling complex systems as well as features intended for future versions of Evoland. Our paper presents the actual mechanism of Evoland and a fully developed case study involving interacting ecological and economic development processes. A conceptual diagram of Evoland is given in Fig. 1. Evoland was designed to investigate alternative futures (Baker et al. 2004) that may result from different policy approaches in socialecological systems (SES) in the flood plains and riparian forests at the junction of large rivers. This type of system is among the most dynamic of any landscape and is rich in biological and socioeconomic diversity as well as natural habitat and built-environment complexity. These areas are highly valued for their access to water and transportation and as sites for industry, food and fiber production, recreation, and natural beauty. Of world cities with more than 1 million inhabitants, $58 \%$ are on or adjacent to the flood plains of large rivers (C. Smith, personal communication). A primary rationale for an alternative futures model like Evoland is to evaluate simulated patterns of change deriving from different policy intentions, determine the most affected locations, and, conversely, identify the locations in which policy can have the most impact with respect to specific intentions or goals. Typical of alternative futures analyses, Evoland is more likely to provide reasonable estimates of the bounds of system behavior rather than to predict specific outcomes (Nassauer and Corry 2004). Future versions of Evoland are planned to support role playing and evaluating factual knowledge in specific settings, as described by Janssen and Ostrom (2006).

\section{State variables and scales}

A vector-based internal GIS manages most state variables in Evoland. This internal GIS does not have as many features as commercial and many open-source GIS. However, it does support a rich spatial query language, many table operations, and a variety of visualization modes. The 7091-ha McKenzie-Willamette study area (Fig. 2) has 16,005 separate polygons, or, as they are called in Evoland, integrated decision units (IDUs). These management units are homogeneous with respect to tax lot, land use and land cover (LULC), floodplain status, and riparian association. The scale of these polygons corresponds to the minimum mapping unit (Evans and Kelley 2004). These polygons are derived by the geographic intersection of thematic map layers, including tax lots, flood zone maps, habitat suitability, and LULC maps. Geographic intersection has the effect of subdividing polygons into smaller and smaller IDUs that have more and more attributes. The spatial attributes from the intersected thematic layers and other attributes are stored in the internal database. Database attributes represent the state of the landscape during the simulation and may be changed by agent and environmental processes. Policies transcribed into the Evoland policy language refer to these attributes. Appendix 2 lists the significant attributes, and their sources, managed by the GIS. For this study, the temporal scale is a biennial time step forwarded 50 $\mathrm{yr}$ into the future.

Unlike agents in many ABMs, those used in this case study do not move from space to space and are identified by the space they occupy (Brown et al. 2005). Evoland agents are defined by a set of preferences for ecosystem health and economic values that are attributes of the IDU they occupy. These preferences and other attributes of the spatial database are manipulated by a mechanism characteristic of those used in cellular automata (Benenson and Torrens 2004, Dietzel and Clarke 2004, Holland 1998, Wolfram 1983). Unlike cellular automata, Evoland uses a polygon-based representation of space rather than a regular grid of cells, and the neighborhoods in Evoland are obtained using spatial operators such as "next-to" and "within- $x$-distance-of," rather than by the cell indexing of von Neumann (four cells) or Moore eight-cell neighborhoods.

\section{Process overview and scheduling}

The diagram in Fig. 3 gives an overview of Evoland scenario processing. In Evoland, a scenario is the unit of analysis. Scenarios differ from each other by the contents of their policy sets. Each scenario consists of many runs. The stochastic parameters of each run are sampled from their distributions at the 
Fig. 1. Conceptual framework showing the major components and relations of the social-ecological system represented in the Evoland model. The dashed arrows indicate flows of information. The solid arrows indicate changes to the landscape. The agent decision-making process, which is repeated annually for each parcel, is tantamount to stochastic sequential optimization of the landscape for societal goals and agent preferences. The process begins when the agent selects the subset of policies admissible on the current parcel, e.g., riparian policies for riparian parcels. Next, admissible policies are ranked on the basis of policy effectiveness ratings. One rating for each of the ecosystem health and economic values indicates the capacity of the policy to change the landscape on that metric. Two factors contribute to the highest rankings. One is the match between policy ratings and agent preferences. The other depends on the magnitude of the landscape deficiencies and the capacity of the policy to correct them; this factor is proportional to the magnitude of the deficiencies. Finally, one of these policies is chosen stochastically, with the highest ranking policy the most likely to be selected. A landscape evaluation provides feedback to the decision algorithm regarding deficiencies. Other change processes do not involve agent decision making directly, but do cause landscape changes that affect the landscape state.

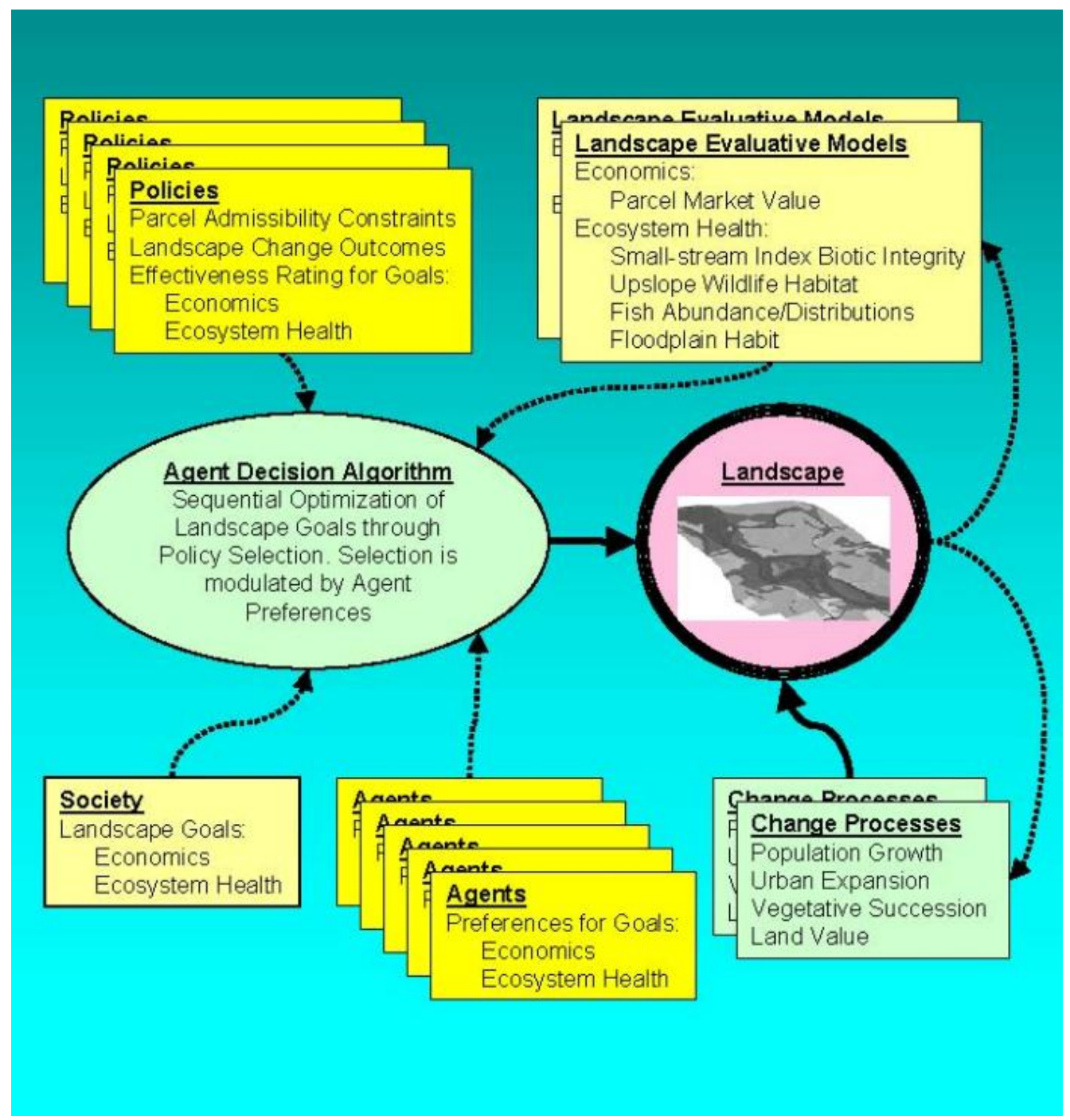


Fig. 2. Context map for the McKenzie study area. The study area is in Lane County, Oregon, which is in the southern part of the Willamette Valley.
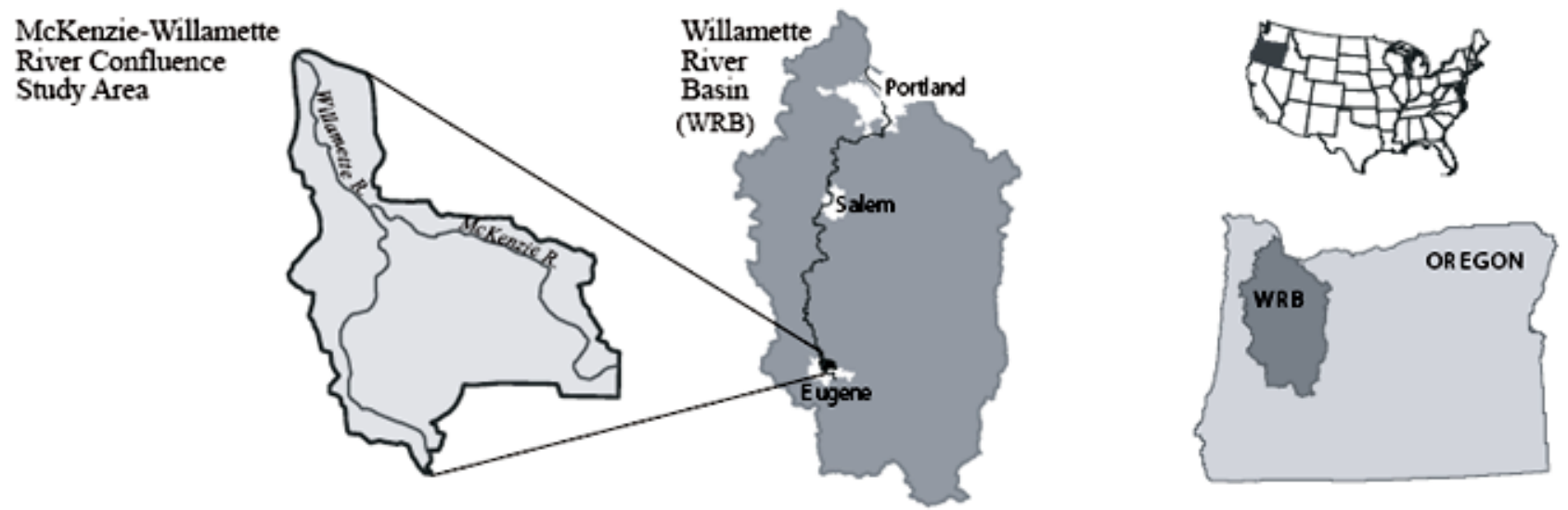

beginning of the run. For each run, the annual loop executes the agent loop and also environmental and other nonagent submodels. The sequence of annual executions of the agent loop is tantamount to sequential optimization at the landscape scale of the valuations for ecosystem health and economics. Optimization may be supported or opposed by agent preferences at the IDU-level, as explained below. Figures 1 and 3 identify a group of submodels called autonomous processes that are executed without agent involvement. These include population growth and location, landscape aging and vegetation succession, and land value adjustments resulting from LULC change. These models alter the attributes of the IDUs. Another group of submodels is called landscape evaluative models. These models compute summary landscape statistics on the economic value of land and the health of four ecosystem services and are affected by both the autonomous processes and agent policy selection. The landscape statistics feed back into the sequential optimization through the agent decision process. Each of these submodels was separately validated with field data and expert review.

\section{Design concepts}

The basic design concept in Evoland is that, when landscape valuations for ecosystem health and economics are deficient or scarce, sequential optimization through policy selection tends to correct those deficiencies. Policy selection may be supported or opposed by IDU-scale agent preferences, but as landscape-scale valuations approach their maximum, i.e., as scarcities disappear, then policy selection will depend solely on agent preferences.

The policies that are input by the user into Evoland scenarios derive from regulations, incentives, management practices, and empirical experience pertinent to the social-ecological system being studied. The policies used in this study are listed in Appendix 3. To formulate a policy to help fish, one could consult field research on the main stem of the Willamette, which shows that fish occur in greater abundance and diversity where forested areas and large wood are available (S. Gregory and R. Wildman, unpublished manuscript). This research suggests that policies that encourage the restoration of riparian forests will help fish. The policy may be targeted to places on the landscape that satisfy certain criteria, e.g., farms next to streams. The policy site-attribute query identifies the parcels from the GIS database in which the policy is 
Fig. 3. Process overview and scheduling for a scenario. A scenario is initialized by loading the policies and distributional information for the stochastic parameters that characterize the scenario. For each run of the scenario, the stochastic parameters are sampled from their distribution. The annual loop runs the agent loop and also the landscape evaluators and the environmental processes independent of agent behavior, including the population and vegetation succession models. Note that the policy ranking index has two components: One depends on agent preference, and the other on current landscape valuations for ecosystem health and economics. The latter component is proportionately larger according to the magnitude of landscape deficiencies or scarcities. The effect of annual executions of the agent loop is tantamount to stochastic sequential optimization for ecosystem health and economics. An IDU is an integrated decision unit or a polygon in the landscape managed by an agent.

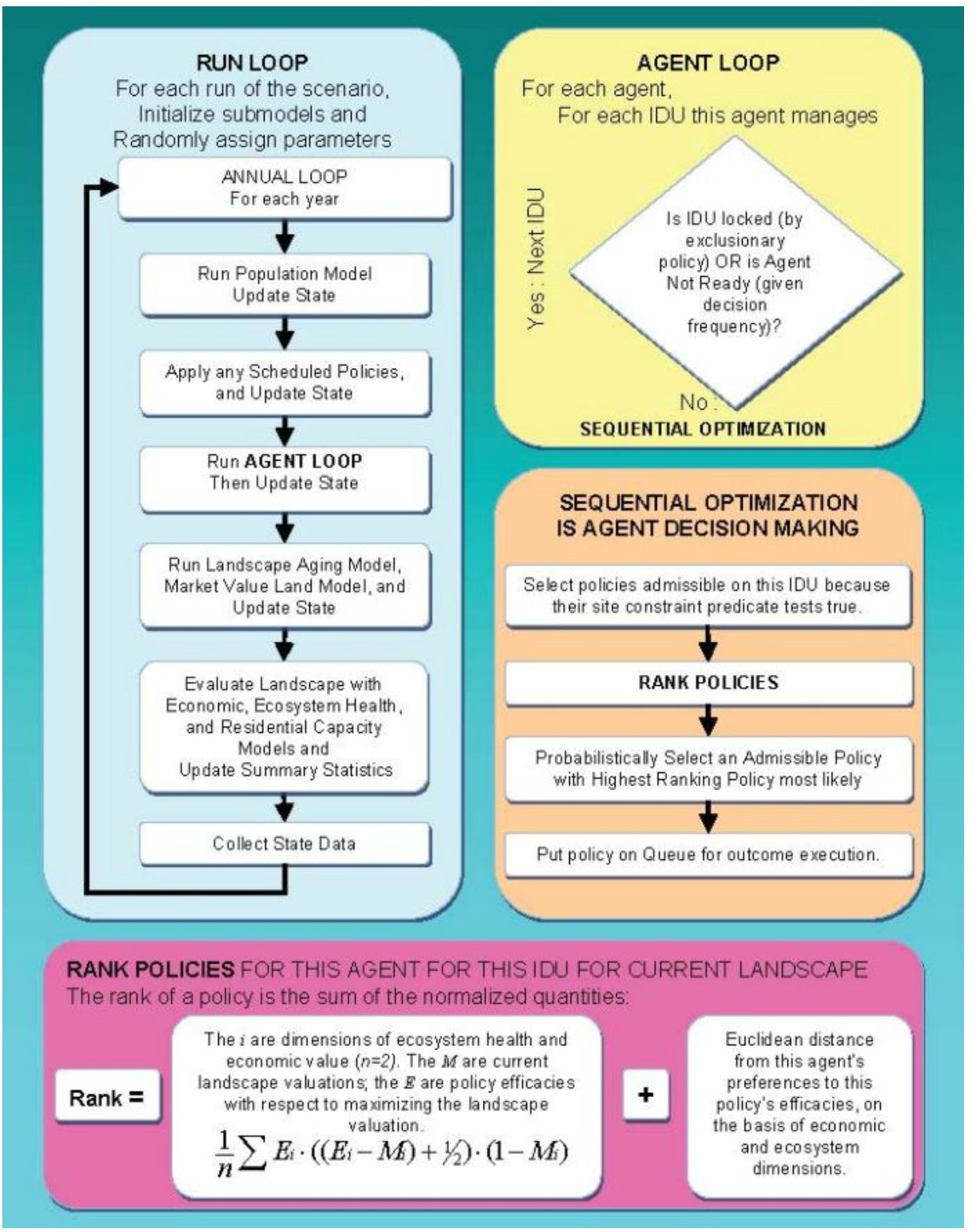


admissible. The query is similar to a SQL SELECT statement. For example, a fish conservation policy could be made specifically admissible on IDUs that satisfy the following site-attribute query:

\{Outside Urban Growth Boundary\} and (LAND COVER is \{Rural non-vegetated unknown or $\{$ Hay/Pasture/Fallow $\}$ or $\{$ Grass Seed/Grain $\}$ or \{Row/Field Crops $\}$ or $\{$ Other Vegetation\}) and \{Distance to Stream $<100$ meters

This constraint, edited for readability, selects IDUs outside the urban growth boundary with one of various unbuilt land covers. A policy without an outcome or action is incomplete. A fish conservation policy outcome provides habitat for fish:

Buffer (100 m, \{Water\}, \{Forest semi-closed mixed $\}$ and $\{$ Conserve\}:20; \{shrubland $\}$ and \{Conserve $\}: 80$ )

This outcome, edited for readability, changes a single IDU if and only if the agent managing the IDU chooses this policy during decision making. A 100-m buffer along the stream will be carved out, and the resultant IDU will be marked for conservation in the GIS database. The outcome specifies a $20 \%$ likelihood that the resultant IDU will be marked as a semiclosed mixed forest in the GIS and an $80 \%$ likelihood of shrub land. This outcome uses the dynamic polygon subdivision feature of the Evoland GIS and demonstrates that outcomes may be specified stochastically. Subsequent to policy outcome, the Evoland submodel for vegetation succession will continue over the course of time to change the attributes of this IDU, unless another agent-decision on the IDU interrupts the process.

The Evoland visual policy editor makes it easy to construct policies and visualize where the IDUs selected by the query exist (Fig. 4). The editor interface helps the analyst to build a site attribute query from drop-down lists of database attributes and logical and spatial operators. The yellow hatching on the study area map shows that the policy being edited is supposed to be applied to the agricultural and forest lands in the upper and right sides of the study area. Similarly, the analyst uses the editor to build an outcome. Policies also have other properties. A policy may be mandatory, in which case that policy must be chosen by the agent during the decision process if the site attribute query evaluates true. Policies may also exclude the application of other policies to the same IDU for a specified stochastic period of time. Policies may specify a window of time outside of which they may not be selected. Finally, policies have a pair of effectiveness scores, which we term efficacies or intentions, that quantify the long-term expected landscape economic value and ecosystem health if the policy were to be preferentially selected. In the fish conservation example, the policy intention has a negative economic efficacy of -1.0 and a positive ecosystem health efficacy of 2.0. Either the expertise of the user assigns the efficacies, or the initial setup of Evoland initializes them.

The emergent properties of coupled SES derive from modeling decisions made by agents in an evolving landscape (Michner et al. 2001). The agent decision algorithm of Evoland is a type of stochastic sequential optimization that is subject to agent preferences. From the point of view of the agents, over the lifetime of a model run the algorithm generates for each agent a sequence of policy choices and resultant landscape outcomes. Adaptation from agent actions emerges at the landscape level when the mode of policy selection shifts from one dominated by agent preferences to a more altruistic mode that tends to correct emerging landscape-scale deficiencies or scarcities in ecosystem health or economic status (Fig. 3). In other words, the agent decision process sequentially optimizes landscape-level ecosystem health and economic value, but may be supported or opposed by agent preferences at the IDU-level.

For each IDU an agent manages, the optimization algorithm begins policy selection by ranking the admissible policies based on their ecosystem health and economic scores. The score consists of an equally weighted index in two parts. The first part, which is independent of agent preferences, is a function of the policy efficacies and the current landscape-level statistics (Fig. 3). The second part is the normalized Euclidean distance between the vector of agent preferences and the vector of policy efficacies. After the policies are ranked, one of them, usually the policy with the highest ranking, is chosen probabilistically. The sequential optimization or agent-decision process as described tends to choose policies that have intentions or efficacies that match agent preferences when the current landscape is maximized with respect to ecosystem health and economics. However, if the landscape is deficient or scarcities exist, then the process tends to choose 
Fig. 4. Evoland policy editor. The policy editor integrates GIS functionality and the Evoland spatial query language. The yellow-hatching in the figure shows where on the landscape the policy is admissible. In this policy, the hatching identifies rural land that is suitable for development. The yellowhatched parcels are selected by the site attribute query, an expression similar to an SQL Select statement. The policy editor assists the analyst in writing policies in the Evoland spatial query language.

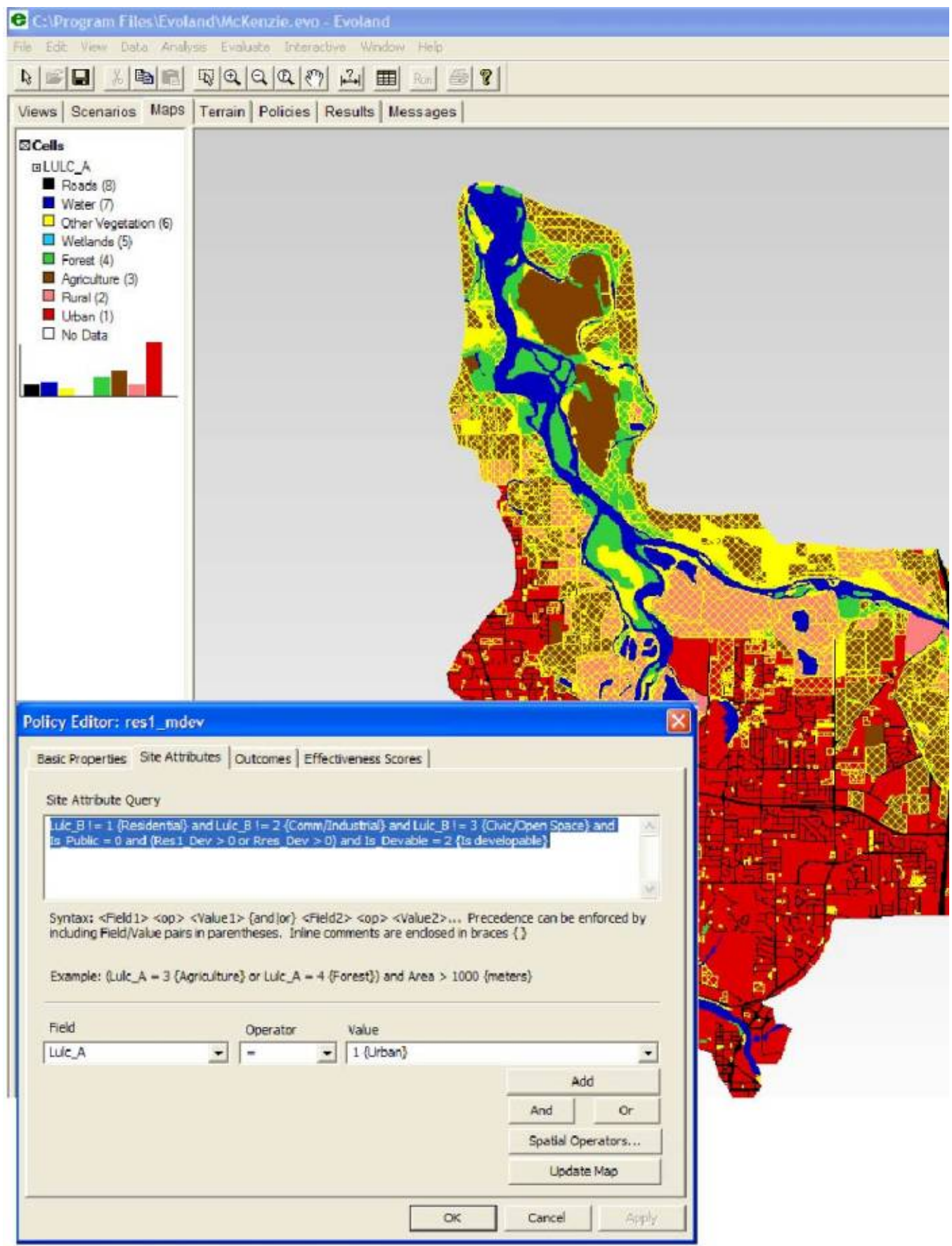


policies that address those deficiencies modulated by agent preferences. Note that the core Evoland mechanism considers three determinants, each of which is a vector quantity based on ecosystem health and economic performance. These determinants are agent preferences, landscape-scale statistics, and policy efficacies or intentions. These values are commensurable because they have been standardized to be uniformly distributed on the interval $[-3,3]$.

Evoland agents do not directly interact. The capacity for indirect agent interaction, however, is provided by policies formulated with spatial operators that consider the status of neighboring IDUs. These policies "sense" the environmental changes caused by other agents as reflected in the attributes of neighboring IDUs. The landscape-scale feedback from the evaluations of ecosystem health and economic value also factor into the decision process and can be considered the basis for indirect agent interaction.

Evoland is stochastic in several ways. Policy selection from the ranked policies is stochastic for each decision, with the highest ranked policy most likely to be chosen. However, because the highest ranking policy is not always chosen, the sequential optimization algorithms may escape local optima traps. This feature may be seen to represent lessthan-rational agents. Also, the submodels have stochastic parameters that represent the inherent uncertainty or variability in the system so that ensembles of results in some sense represent the range of what is possible.

\section{Initialization}

The Evoland 3.5 platform uses geospatial data layers converted into a single IDU map layer that reflects the state of the study area in about the year 2000. Figure 5 shows the initial year 2000 conditions for the nine coarsest LULC classes. The study area includes a diversity of economic activities. The northern part of the study area (18\%) is largely agricultural, dominated by grass seed, pasture, grass hay, grains, irrigated crops, orchards, and a number of other crops. Forested areas occupy $13 \%$ of the study area. Eugene-Springfield is the major urban area in Lane County, with a 2000 population of 190,757 (U.S. Bureau of the Census 2005). The Eugene-Springfield urban portion of the study area (34\%) includes a complex mix of high tech, manufacturing, education, and service industries coupled with the older extractive industries in agriculture and forestry (Fig. 6). Fiftyfive percent of the urban portion is in the historic flood plain (Fig. 7), and represents a variety of urban population densities (Fig. 8). The sources for each of the attributes are given in the Table A2.1 (Appendix 2).

For the McKenzie-Willamette study area, agent values were derived from an analysis of voting behavior on environmental ballot measures in the November 3, 1998, Oregon-United States midterm election. A content analysis of pro and con statements published in the Voters' Pamphlet that was mailed to all registered voters by the State of Oregon was used to interpret precinct-level voting results. In general, analysis of the study area showed that rural agents preferred economic values whereas urban agents preferred ecological values This finding is common to other studies (Dunlap et al. 2000, Steel et al. 2003, Gelissen 2007). Confidence that the inferences about values apply beyond the election is suggested by research that indicates that the normative beliefs that determine people's actions are quite stable (Rokeach 1973, Karp 2000, Davis and Wurth 2003, Manfredo and Dayer 2004, Sabatier et al. 2004). A geostatistical model was used to disaggregate the results from voting precincts to the much finer spatial scale of the Evoland IDU. Agents are mapped one-to-one with IDUs in Evoland. The model is complex, and only the basics are described here and elaborated in Appendix 1. The model required an estimate of the spatial covariance of voting results on environmental ballot measures that polarized voters with respect to economic and ecosystem preferences. The model also used correlations of the vote with population density and real market value of land measured at the fine scale of the IDU. Initially, all agents in a voting precinct were homogeneous with respect to voting preference. A maximum a priori probabilityannealing algorithm iteratively perturbed agent preferences to reflect both the voting covariance and the fine-scale pattern of population density and land value so as to reconstruct within-precinct variability. Agent preferences for both economics and ecosystem health were derived from the resultant map, and the negative correlation (-0.8) between preferences was found by content analysis. The generated agent preferences were loaded into the IDU database. In the case study, agents did not 
Fig. 5. Initial coarsest articulation of nine land-use and land-cover (LULC) classes in the McKenzieWillamette study area. This was the distribution of LULC classes in 2000. The Willamette River flows from south to north through the study area. The McKenzie joins the Willamette from the east.

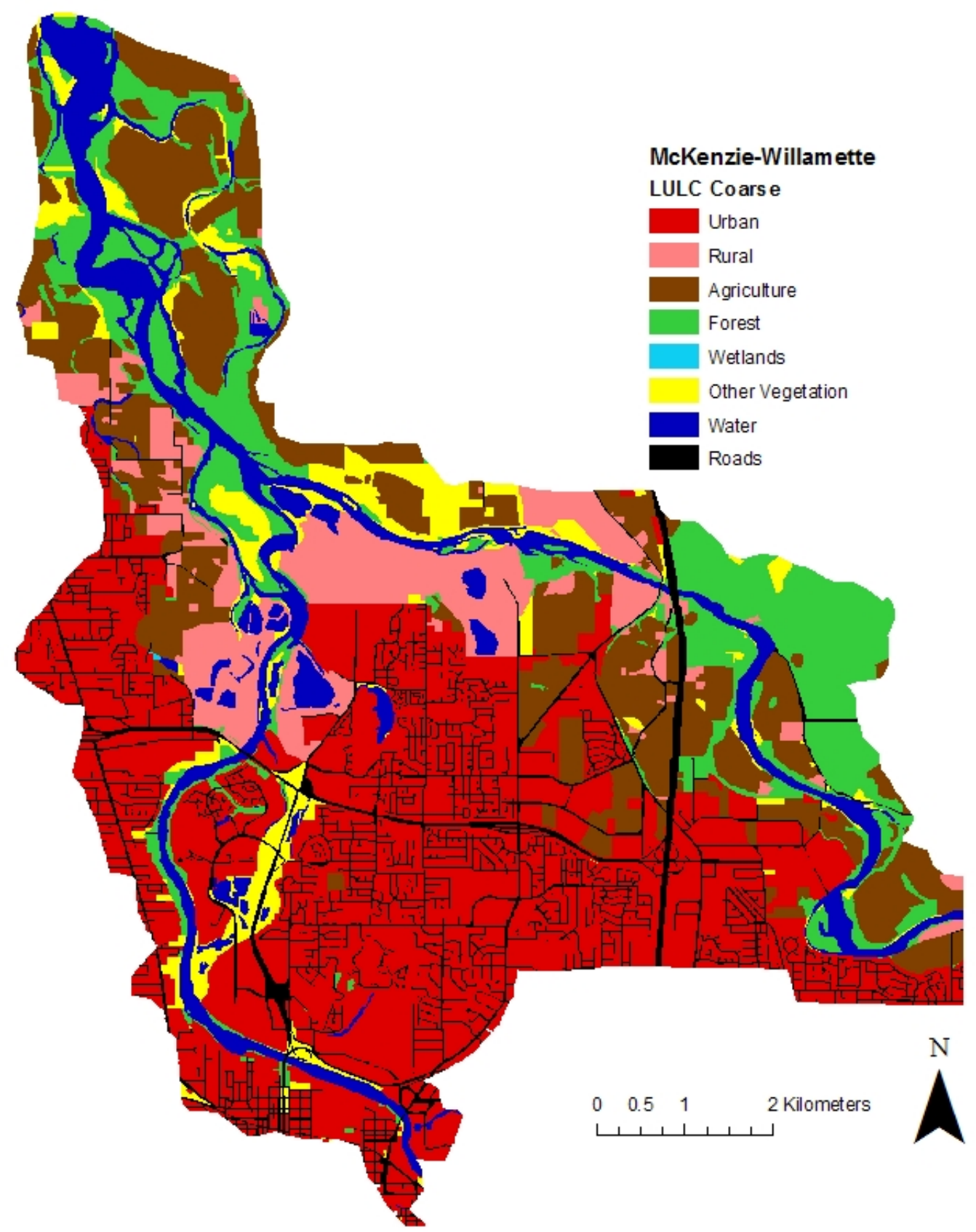


Fig. 6. Crossing the center of the study area is the urban growth boundary. The urbanization area is dark gray.

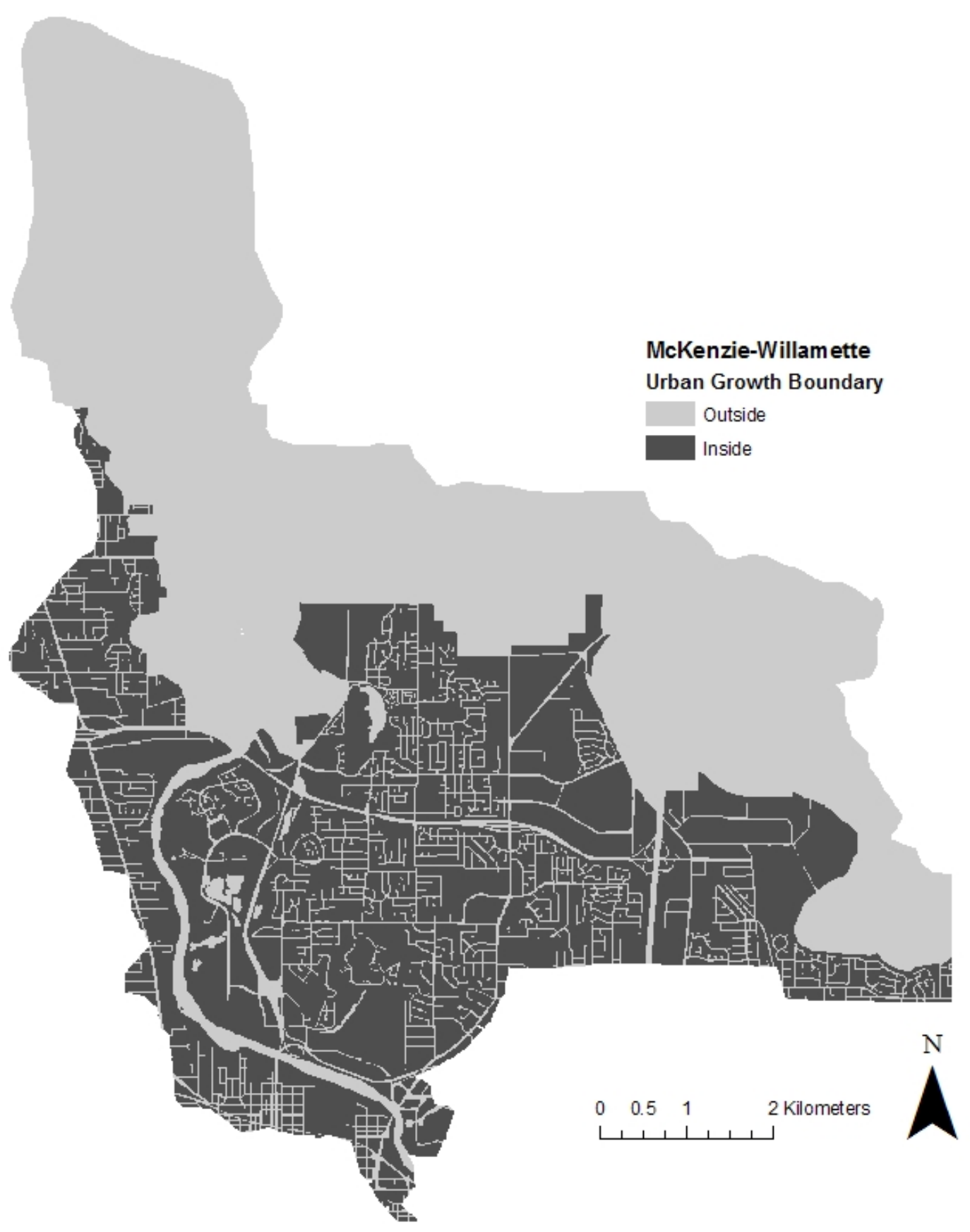


Fig. 7. The Federal Emergency Management Agency 100-yr flood plain is dark gray.

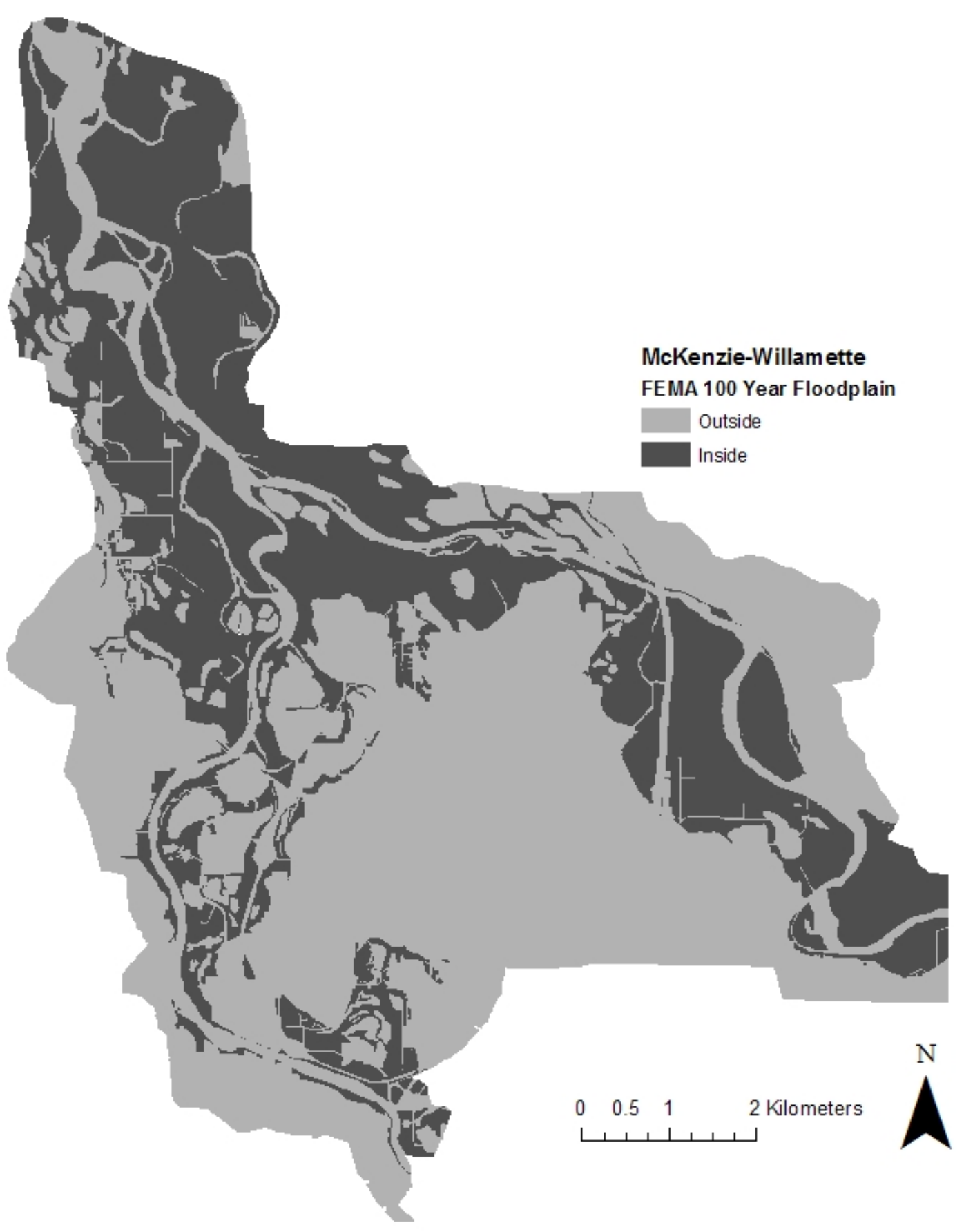


Fig. 8. Initial population densities in the study area are shown with darker shades representing higher densities. The ranges are given in people/ha.

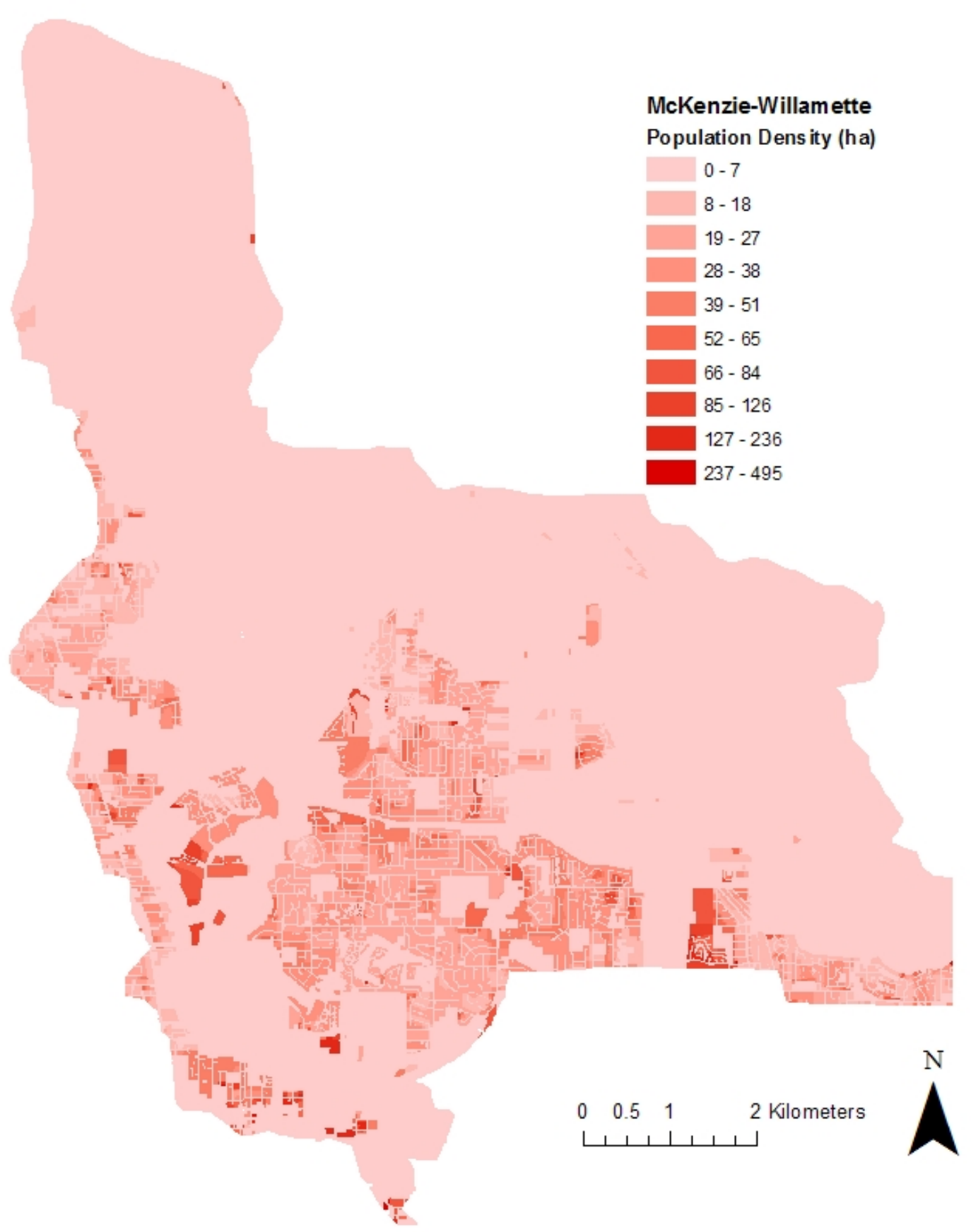


move or change their preferences or values during the course of the simulation. These initial values were used for every run of each scenario.

A scenario is a grouping of policies that will achieve a global objective. For the urban growth problems in the McKenzie and Willamette River junction, policies were crafted for two contrasting scenarios (Appendix 3). The efficacies, i.e., intentions, of the policies were assigned using a combination of expert knowledge and an Evoland heuristic. The heuristic quantifies the effects of a single policy by comparing the "before" and "after" landscape values of ecosystem health and economics in a sandbox simulation that runs from initial conditions. Scenario initialization also requires initial values for a number of parameters, including population growth rate, societal goals for economic and ecosystem health resilience, and a number of parameters that specify urban development in terms of desired population density and developable land. The parameter values for the scenarios in this case study are listed in Appendix 4.

Two general scenarios for urban expansion were created to set the bounds on what might be possible for the McKenzie-Willamette study area. One scenario, fish conservation, tried to accommodate urban expansion, but gave the most weight to policies that would produce resilience and ecosystem services to restore threatened fish populations. The other scenario, unconstrained development, reversed the weighting. The 35 policies in the fish conservation scenario are designed to maintain urban growth boundaries (UGB), accommodate human population growth through increased urban densities, promote land conservation through best-conservation practices on agricultural and forest lands, and make rural landuse conversions that benefit fish. In the unconstrained development scenario, 13 policies are mainly concerned with allowing urban expansion in locations desired by landowners. Urban expansion in this scenario was not constrained by the extent of the UGB, and the policies are not intended to create conservation land uses.

The fish conservation scenario is based on considerations that include the listing of Chinook salmon (Oncorhynchus tshawytscha) and steelhead trout (Oncorhynchus mykiss) as threatened species under the federal Endangered Species Act (NOAA 2005) in the McKenzie-Willamette confluence. Scientific study has shown that forested lands and large wood in streams are correlated with fish abundance and diversity (S. Gregory and R. Wildman, unpublished manuscript). Research shows that fish abundance is greater in areas in which there are trees that produce shade, fall into streams, make habitats for macroinvertebrates, and provide protection for fish (Kauffman et al. 1997; S. Gregory and R. Wildman, unpublished manuscript). Thus, policies that convert rural lands to forest are emphasized to reduce scarcities of fish habitat. For lands in agriculture and forestry, policies are created to encourage best conservation practices such as those in the U.S. Farm Bill (NRCS 2002) and put lands into older forest age classes. In the fish conservation scenario, urban populations, commercial uses, and industrial growth are held within the UGB, which expands according to the rules of Oregon's land-use planning laws.

The unconstrained development scenario is based on consideration of the effects of Oregon Ballot Measure 37 (http://www.sos.state.or.us/elections/n ov22004/guide/meas/m37 text.html), which passed in 2004 (Jaeger 2006). This measure requires public entities that enact or enforce land-use regulations that affect the real market value of property to either compensate the owner or grant a waiver to the regulation. Because no source of compensation was provided for in the ballot measure, development is allowed more or less everywhere on private lands except those considered unsuitable for building or designated for conservation. Oregon policies allow low-density housing on the banks of rivers and in rural areas, thus waiving current land-use controls. Urban densities are not forced to increase.

\section{Time series inputs}

In the Grimm et al. (2006) protocol, inputs are defined as imposed dynamic state variables that drive the simulation. For this case study, total population was imposed using an annual growth rate of $1.5 \%$ (Hulse et al. 2002).

\section{Submodels}

The purpose of the landscape aging submodel is to manage vegetative succession in forested, wetland, and other vegetated IDUs (Appendix 5). The model is coded as a transition matrix based on research pertinent to this area. The model is detailed in Table A5.1. 
The purpose of the population growth submodel is to forward population through time and to add or remove population changes conditional upon changes in land use that affect the residential density class of the IDU (Appendix 6). In 2000, the study area population was 40,000 , and projections indicate that it will likely double in the next $50 \mathrm{yr}$. From 1990 to 2000, Lane County, which contains the study area, grew by $14 \%$ or at an annualized rate of $1.5 \%$.

The purpose of the residential capacity submodel is to periodically enlarge the UGB to create more land for residential development to accommodate population growth as required by Oregon's urban growth law (Appendix 6). When the submodel detects that urban population density has exceeded a threshold, then the UGB is expanded to accommodate approximately $10 \mathrm{yr}$ of growth. Many urban development policies in the case study are admissible only within the UGB.

The purpose of the economic landscape-scale evaluator is to compute at each time step a statistic that is input into the stochastic sequential optimization algorithm that underlies agent decision making. The statistic affects the agent-independent component of rankings used to choose policies. The value is a summary statistic of the real market values of all IDUs expressed on a per capita basis. Real market values are predicted by a hedonic model as a function of neighborhood, proximity to amenities and the central business district, and land use and land cover, e.g., agricultural, forest, commercial, industrial, and high- and low-density residential. The evaluator was derived from regression analysis (Hascic 2006) and is described in Appendix 7.

The purpose of the ecosystem health landscapescale evaluator is to compute at each time step a statistic that is input into the stochastic sequential optimization algorithm. We interpret this value as a measure of ecosystem resiliency, because it is computed as an average of component models that consider biophysical condition, biophysical potential, and infrastructural constraints on restoration of biophysical function (Hulse et al. 2002), biotic integrity (Van Sickle et al. 2004), riparian and upland habitat suitability (Adamus et al. 2000), species-habitat relationships (U.S. Environmental Protection Agency, unpublished manuscript), and fish number and species richness (S. Gregory and R. Wildman, unpublished manuscript). This model is described in greater detail in Appendix 8.
These economic and ecosystem health evaluators provide feedback to the optimization that is embodied in the agents' decision-making process. To ensure that the process is not biased because of heteroscedasticity to favor the evaluator with the largest variance (Brown et al. 2002), these landscape evaluators are designed to return values uniformly distributed on the interval $(-3$ to +3$)$. The value -3 represents the least amount of resilience, stability, or productivity, depending on the submodel, and +3 represents the most.

\section{RESULTS}

Evoland embodies the approach to agent-based modeling (ABM) in which, because of stochastic elements, no single run is representative of the outcomes for the system under study. An analysis consists of developing and testing multiple scenarios, each defined by a specific set of policy and model parameters. Each scenario produces ensembles of stochastic simulations of future landscape conditions with means and variances consistent with the assumptions of the scenario (Bankes 2002a). Analysis of the results that suggests modification of the inputs is called "iterative scenario development" and may lead to inductive reasoning (Bankes 2002b). The iterative process that generates successive sets of results by manipulating the specified sets of policies may lead to the discovery of significant patterns (Axelrod 2003) that indicate the limitations on the future effects of policies applied to complex adaptive systems (Bankes 2002a). We used this approach in our case study.

Table 2 compares the initial conditions common to all scenarios to the average outcomes from an ensemble of 50 runs each for the fish conservation and unconstrained development scenarios at the end of $50 \mathrm{yr}$. A video capture movie of an example of each scenario is at http://evoland.bioe.orst.edu/Pub lications.htm. Figure 9 shows the results for a typical conservation scenario after $50 \mathrm{yr}$. In the fish conservation scenario, most rural residential, rural nonvegetated, agricultural, and other vegetation areas have turned to forest. Other vegetation consists of grassland and shrub land. Note that comparison of Figs. 5 and 9 shows that substantial sections of the northern portion of the study area have converted to forest. In the ensembles for the fish conservation scenario, the urban area increases by an average of 5.9\%. Average population density increases from 17 to 29 persons/ha. 
Agricultural land declines by more than half, from 18.1 to $7.4 \%$ (Table 2). Because the UGB policy holds, most population growth is accommodated within the UGB. Forest more than doubles, from 13.4 to $30.8 \%$. As a result, stream conditions for fish improve over the 50-yr run from 0.21 to 2.93 (Fig. 10). The overall improvement in ecosystem health is from -1.27 to 2.97 . Evaluative metrics of resilience are scaled from -3.0 to +3.0 , where the range represents the expected minimum and maximum over all years of all scenarios. Thus, the scores near 3 indicate that the expected maximum potential has almost been attained.

The residential expansion allowed in the unconstrained development scenario (Fig. 11) increases the built-up area by $29 \%$ (Table 2). Agriculture decreases from $18.1 \%$ of the study area to $3.9 \%$, and forest decreases from 13.4 to $8.4 \%$. Figure 11 shows residential growth along streams and in agricultural areas that, under the fish conservation scenario became forested (Fig. 9). With unconstrained development, stream conditions for fish drop from 0.21 to -1.66 (Table 2). Overall ecosystem health decreases from -1.41 to -2.42 . Nearly two thirds of the study area are consumed by policies that convert agricultural and forest IDUs into low-density residential land use.

\section{Iterative scenario development: protection of agriculture and forestry with unconstrained development}

In both the fish conservation and the unconstrained development scenarios, agriculture decreases and is replaced by forests and urbanization. For the fish conservation scenario, agricultural declines 59\% from initial conditions, and in the unconstrained development scenario, the decline is $78 \%$. Agriculture appears to take the brunt of both fish protection and urban expansion.

Because this decline seems indefensible, and to set up an opportunity to apply inductive reasoning to a series of variations on scenarios, we define a new scenario by adding policies to protect agriculture and forestry to the unconstrained development scenario. An agricultural reserve allows agents to protect their agricultural and forest lands from urban or other development. An example is the agricultural reserve policy in British Columbia (Pierce and Furuseth 1982).
For the unconstrained development scenario with agricultural and forest reserves, policy selection decisions lead to agricultural declines of $36 \%$, which is less than the $78 \%$ decline in the unconstrained development scenario without agricultural and forest reserves. Although forest lands also decline, the decline is only $11 \%$ as opposed to $37 \%$ with unconstrained development. Ecosystem health is negative, and the fish evaluative score is only slightly positive with agricultural and forest reserves (Table 3 ). These results suggest the hypothesis that conserving agriculture at the expense of restricting the forest and urban expansion can keep evaluative scores for ecosystem health and fish conservation closer to initial conditions. Further, 23.5\% more agriculture and forest lands were protected with the agricultural and forest reserve policy. However, this is still a $25 \%$ decrease from initial conditions.

\section{Iterative scenario development: combining the conservation and development policies, and further variations}

What if the policies in the fish conservation and unconstrained development scenarios are run together as a scenario? This is not unlike real conditions, under which conservation policies are added to correct the problems resulting from development but development policies still remain active. Note that this combined scenario included the UGB. In general, the average of the ensembles using the combined set of policies fell between the fish conservation and unconstrained development scenarios (Table 4). The combined scenario had $39 \%$ less agricultural and forest land than the fish conservation scenario, and the built area was $25 \%$ larger than in the fish conservation scenario (Table 4). The fish and ecosystem health scores were lower, but still led to positive improvements. Ecosystem health declined the most, but still ended above initial conditions. Dropping the UGB and adding an agricultural and forest reserve policy kept the built area about the same as with the UGB policy. Agricultural land increased threefold, and forest land declined. The fish evaluative score was nearly the same as with the UGB policy, but the ecosystem health score dropped by an additional third. The decline in ecosystem health occurred because the selection of the agricultural conservation policies did not affect many riparian areas. Agriculture occupied mainly upland areas, which reduced the evaluative scores for small-stream macroinvertebrates 
Table 2. Distribution of land uses between initial conditions and percent land use in year 50 for fish conservation and unconstrained development scenarios. The percents are the average of 50 model runs. "Built" refers to residential, commercial, and industrial development and associated infrastructure. "Agriculture" is land in some type of agricultural land use. In addition to field crops agriculture includes nurseries, Christmas trees, fruit and berries. "Forest" is land in the forest succession categories and types. "Other" is lands like shrubland, public lands, and conservation areas not included in the built, agriculture, or forest categories.

\begin{tabular}{lccccc}
\hline \hline Scenario & Built & Farm & Forest & Other & Total \\
\hline $\begin{array}{l}\text { Initial conditions } \\
\text { (ha) }\end{array}$ & 2375 & 1283 & 950 & 2483 & 7091 \\
$\begin{array}{l}\text { Initial conditions } \\
(\%)\end{array}$ & 33.5 & 18.1 & 13.4 & 35.0 & 100 \\
$\begin{array}{l}\text { Fish conservation } \\
(\%)\end{array}$ & 39.4 & 7.4 & 30.8 & 22.4 & 100 \\
$\begin{array}{l}\text { Unconstrained dev- } \\
\text { elopment }(\%)\end{array}$ & 62.5 & 3.9 & 8.4 & 25.2 & 100 \\
\hline
\end{tabular}

and upslope aquatic animals. Dropping both the UGB and agricultural reserve policies in the combined scenario increased the built area to $56.4 \%$, which was less than in the unconstrained development scenario. Agricultural land dropped significantly, and the ecosystem health evaluative score was 0.28 , whereas the fish evaluative score was 2.26. Conservation policies work in a development situation to improve conditions, but not as much as when conservation is the priority. UGB and agricultural and forest reserve policies produce better results than not having those constraints present.

Figure 12 shows the outcome from combining the fish conservation and unconstrained development scenario policies, including UGB and agricultural and forest reserves. Note how the urban area extends directly north in the middle and along the west side of the study area, but it is not as fragmented as was the case with the unconstrained development scenario (Fig. 9). The selection of agricultural and forest reserves policy keeps the land north of the McKenzie-Willamette river junction in agriculture. Agriculture is also retained in the southeast. Forest is less intensive than in the fish conservation scenario (Fig. 7), but it does surround agriculture on the east side and in the north of the study area.

\section{DISCUSSION}

The iterative approach to modeling used in this case study began with a comparison of two divergent scenarios. Interpreting the results suggested ways to modify the scenarios to both modulate the changes in the extent of forest and agricultural land and understand the interactions of land-use policies, agent preferences, and landscape conditions in social-ecological systems. For example, the fish conservation scenario policies were most effective at improving aquatic health over initial conditions because urban infrastructure was not allowed to develop in the habitat-critical McKenzieWillamette river junction. The fish conservation scenario accommodated a doubling of the population with the trade-off of a higher density (29 persons/ha), but not out of line with existing densities in major U.S. cities reported by the 2000 U.S. census. Los Angeles had 31 persons/hain 2000, and New York City had 100 persons/ha. An additional trade-off was the increase in forested land at the cost of agricultural land. To mitigate the severity of the trade-offs and develop an understanding of the social-ecological interactions, a scenario was synthesized that both protected agricultural lands and permitted additional urban expansion. A surprising result was that agricultural protection and fish-friendly policies can help fish 
Fig. 9. Study area after a typical 50-yr run of the fish conservation scenario.

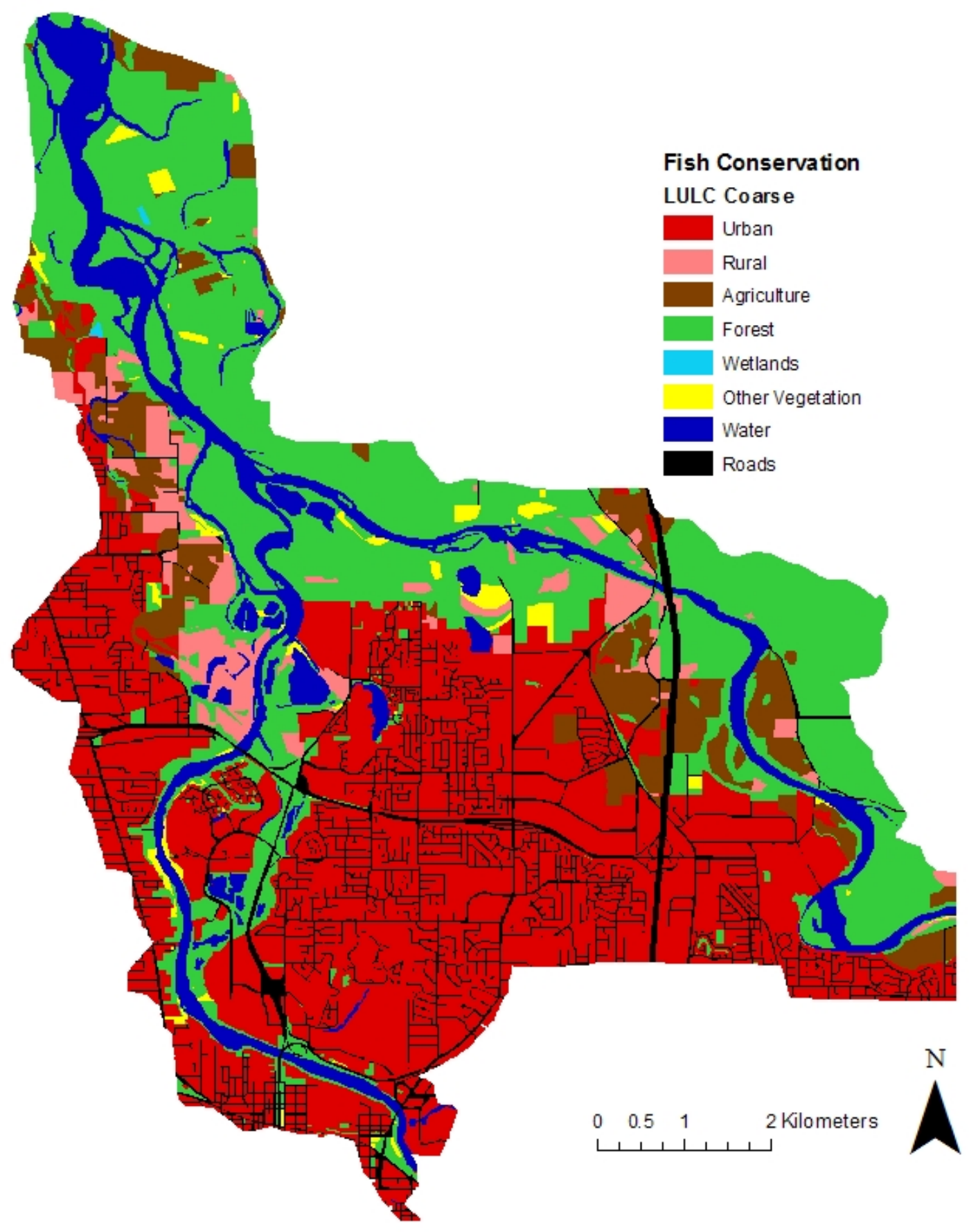


Fig. 10. Average fish and ecosystem health evaluative model scores by year for 50 runs of the fish conservation and unconstrained development scenarios. The fish evaluative model score for the fish conservation scenario (Fish, Cons) is indicated in green, the fish evaluative model score for the unconstrained development scenario (Fish, Dev)in red, the ecosystem health evaluative score for the fish conservation scenario (EH, Cons) in blue, and the ecosystem health evaluative score for the unconstrained development scenario $(\mathrm{EH}, \mathrm{Dev})$ in black.

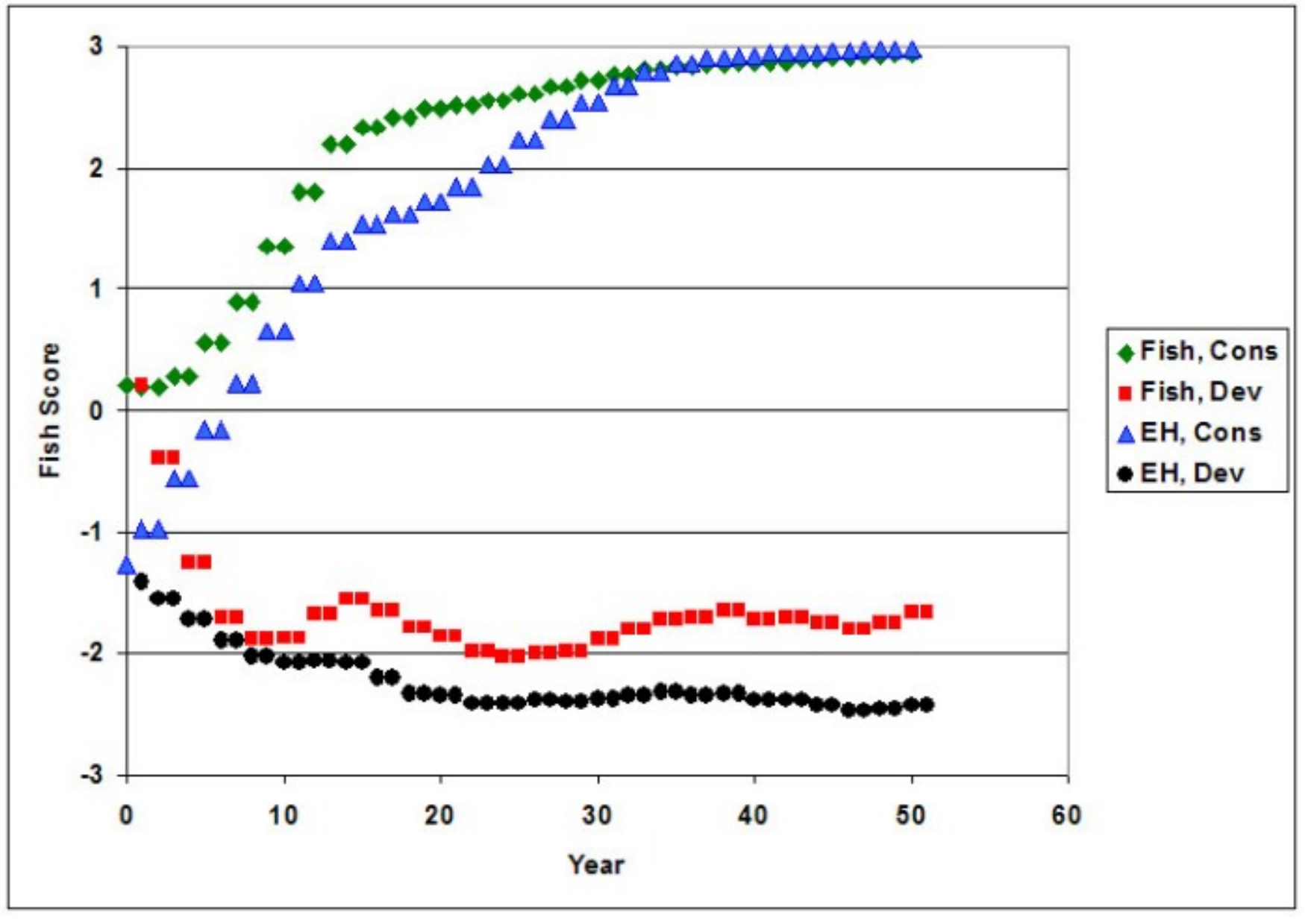

conservation and ecosystem health even when there is urban expansion. However, the improved ecosystem health score in this case is attributable to significant riparian forest, which is the critical factor affecting the ecosystem health submodels, and significant loss of agricultural land.

A question arises, then, about the role of agricultural lands in ecosystem resilience, assuming that forest may not supplant agricultural land. Agricultural enterprises in the United States and Europe face increasing world trade pressures, greater regional concerns about environmental quality, and competition with the productivity of other foodproducing areas. Adapting to these forces will bring change to agricultural enterprises (Ewert et al. 2005, van Meijl et al. 2006). Agriculture can produce ecological services that are becoming scarce and valued by society. The production of ecological services need not be a free good expected from agriculture, but these ecosystem services can be seen as agricultural production that is paid for in 
Fig. 11. Study area after a typical 50-yr run of the unconstrained development scenario.

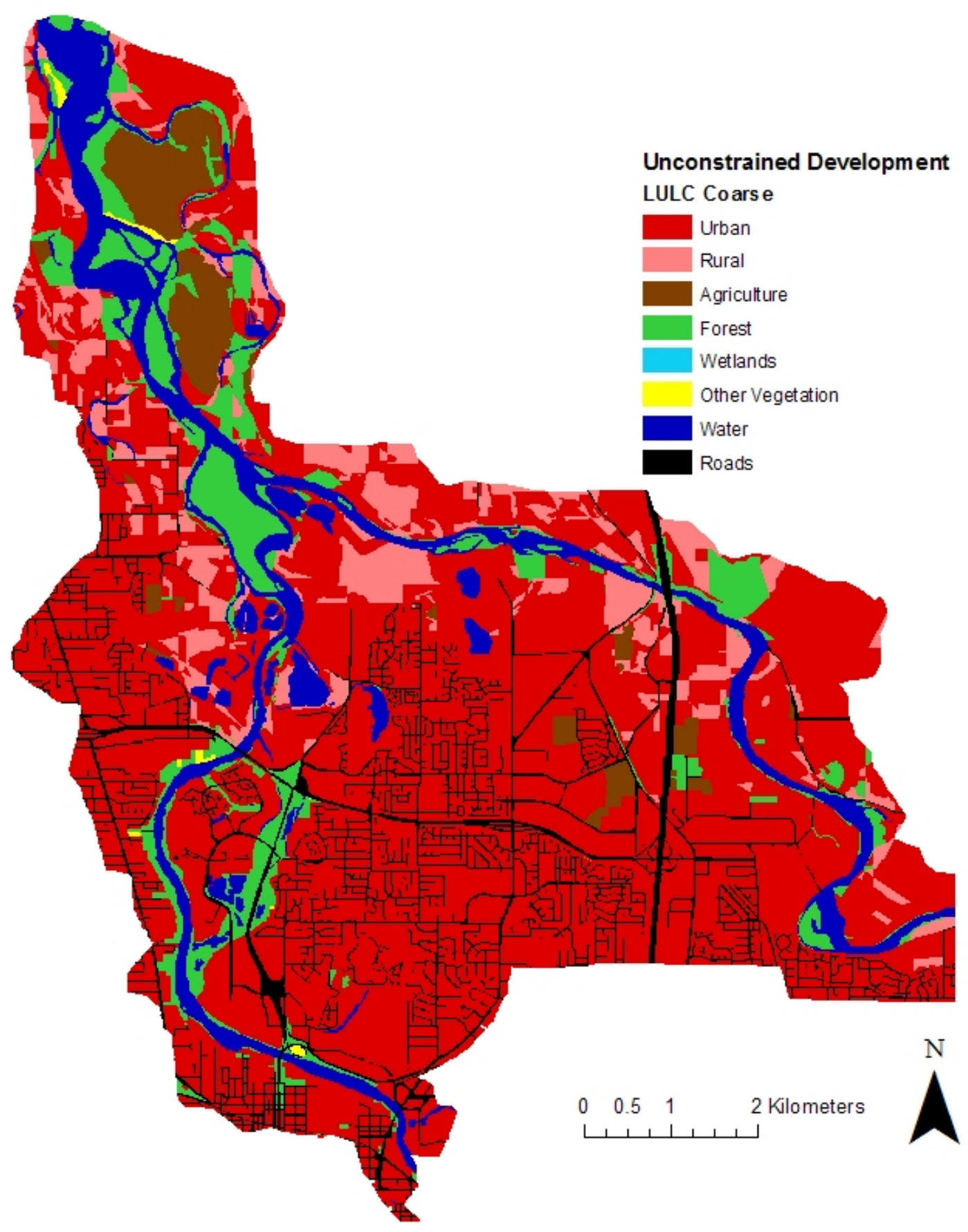


Table 3. Scenarios to protect agriculture add an agricultural and forest reserve policy to the fish conservation and unconstrained development scenarios. Results for the fish conservation and unconstrained development scenarios from table 1 are included for comparison. Reported scores are averages of multiple runs.

\begin{tabular}{|c|c|c|c|c|c|c|}
\hline Scenario & Built & Farm & Forest & Other & Eco-health & Fish \\
\hline Fish conservation & 39.4 & 7.4 & 30.8 & 22.4 & $2.97^{\dagger}$ & $2.94^{\dagger}$ \\
\hline $\begin{array}{l}\text { Fish conservation } \\
\text { with } \\
\text { agriculture and } \\
\text { forest reserves }\end{array}$ & 38.9 & 14.7 & 24.9 & 21.4 & $1.86^{\dagger}$ & $2.89^{\dagger}$ \\
\hline Initial conditions & 33.5 & 18.1 & 13.4 & 35.0 & $-1.29^{\ddagger}$ & $0.21^{\ddagger}$ \\
\hline $\begin{array}{l}\text { Unconstrained } \\
\text { development } \\
\text { with reserves }\end{array}$ & 53.9 & 11.6 & 11.9 & 25.4 & $-1.52^{\S}$ & $0.33^{\S}$ \\
\hline $\begin{array}{l}\text { Unconstrained } \\
\text { development } \\
\text { with urban } \\
\text { growth boundaries }\end{array}$ & 60.8 & 4.0 & 10.3 & 24.9 & $-1.81^{\mid}$ & -0.99 \\
\hline $\begin{array}{l}\text { Unconstrained } \\
\text { development }\end{array}$ & 62.5 & 3.9 & 8.4 & 25.2 & $-2.42^{\dagger}$ & $-1.66^{\dagger}$ \\
\hline
\end{tabular}

${ }^{\dagger}$ Significance of $t$-test is $p<0.01$, df varies.

Initial conditions do not vary.

$\S$ The results from the unconstrained development scenario with agricultural and forest reserves was chosen as the comparator variable.

ISignificance of $t$-test is $p<0.05$, df varies.

new ways such as carbon credits, green banking, and societal purchase of ecosystem services. Creating incentives for agricultural enterprises to grow habitat could avoid the predicted "further abandonment of agricultural land" (Rounsevell et al. 2005:114). The negative effect between agricultural activities and biodiversity is well known (Foley et al. 2005). On the other hand, the attitudes of farmers affect their success in fostering nature values or ecosystem resilience (Schmitzberger et al. 2005). These authors suggest tailoring subsidies to individual farmer needs. Policies that provide financial incentives for farmers to grow socially valued habitats could help improve fish resilience and increase ecosystem services.

The iterative modeling approach to understanding social-ecological systems in this case study may be compared to the one adopted in a previous study of the Pacific Northwest Ecosystems Research
Consortium (PNW-ERC; Hulse et al.2002, Baker et al. 2004). Whereas Evoland is an agent-based policy-research platform, the PNW-ERC study, relied on citizen and expert stakeholders to predict the range of changes that would occur in the Willamette basin of Oregon by 2050 . We developed Evoland in response to perceived problems of extensive stakeholder participation, including cost, and mental constructs that limit predictions of future alternatives. The PNW-ERC study evaluated three scenarios that citizens thought were feasible for the Willamette basin over a 50-yr time horizon, each of which accommodated a doubling of the 1990 human population by the year 2050. One scenario, PNWERC plan trend 2050, was a status quo continuation of existing policies and practices. Under the plan trend alternative, new development occurred at higher densities only within designated urban growth boundaries and rural residential zones, two growth management devices central to Oregon's 
Table 4. Comparison fish conservation, unconstrained development, and combined conservation and development scenarios. The combined scenario shows inclusion of UGBs, both UGBs and agricultural and forest reserves, and without UGBs or agricultural and forest reserves. Reported scores are averages of multiple runs.

\begin{tabular}{lcccccc}
\hline \hline Scenario & Built & Farm & Forest & Other & Eco-health & Fish \\
\hline Fish conservation & 39.4 & 7.4 & 30.8 & 22.4 & $2.97^{\dagger}$ & $2.94^{\dagger}$ \\
$\begin{array}{l}\text { Combined with } \\
\text { urban } \\
\text { growth boundaries }\end{array}$ & 49.4 & 3.1 & 20.1 & 27.4 & $1.85^{\dagger}$ & 2.62 \\
$\begin{array}{l}\text { Combined with } \\
\text { urban growth } \\
\text { boundaries, with } \\
\text { reserve }\end{array}$ & 50.4 & 11.0 & 17.7 & 20.9 & $1.20^{\dagger}$ & 2.59 \\
$\begin{array}{l}\text { Combined without } \\
\text { urban } \\
\text { growth boundaries } \\
\text { or reserve }\end{array}$ & 56.4 & & & & & \\
$\begin{array}{l}\text { Initial conditions } \\
\begin{array}{l}\text { Unconstrained } \\
\text { development }\end{array}\end{array}$ & 33.5 & 18.1 & 16.8 & 22.5 & $0.28^{\S}$ & $2.26^{\S}$ \\
\hline
\end{tabular}

${ }^{\dagger}$ Significance of $t$-test is $p<0.01$, df varies.

${ }^{\ddagger}$ Significance of $t$-test is $p<0.05$, df varies.

${ }^{\S}$ The results from the combined scenario without agricultural or forest reserves was chosen as the comparator variable.

Initial conditions do not vary.

land use planning. In PNW-ERC conservation 2050 scenario, which provided the pattern for the Evoland fish conservation scenario, experts and citizens were instructed to give priority to the restoration and preservation of ecosystems when devising policies governing land and water uses. As with plan trend 2050, high-density urban development was emphasized, but conservation 2050 clustered new rural housing, thus minimizing its footprint and leaving the remainder of newly developed rural parcels in natural vegetation. PNW-ERC development 2050, a future in which market forces dominate land-use decisions, produced the third scenario, which provided the pattern for the Evoland unconstrained development scenario. In this alternative, current land-use policies were relaxed and new development was allocated at lower densities over a larger area.
Table 5 shows the citizen-based PNW-ERC scenarios for the McKenzie-Willamette study area. In 1990, land uses were divided nearly evenly between urban and agricultural land uses, with forest at $11.2 \%$. Table 5 shows the estimated percentage of LUCC in 2050 for the three scenarios compared to 1990 conditions. The land-use categories in Table 5 approximate those used in Evoland, but do not duplicate them. In general, the direction of change, but not the magnitude, is the same as shown by Evoland, which is evident when Table 5 is compared with Table 2 .

The magnitude of differences in the PNW-ERC 2050 scenarios, however, is smaller than with Evoland. The difference in the amount of urban area between plan trend 2050 and initial conditions is $17.5 \%$. The conservation 2050 scenario has only 
Fig. 12. Study area after a typical 50-yr run of the combined policies in the fish conservation and unconstrained development scenarios in which the urban growth boundary and the agricultural and forest reserve policies are included. LULC stands for land use and land cover.

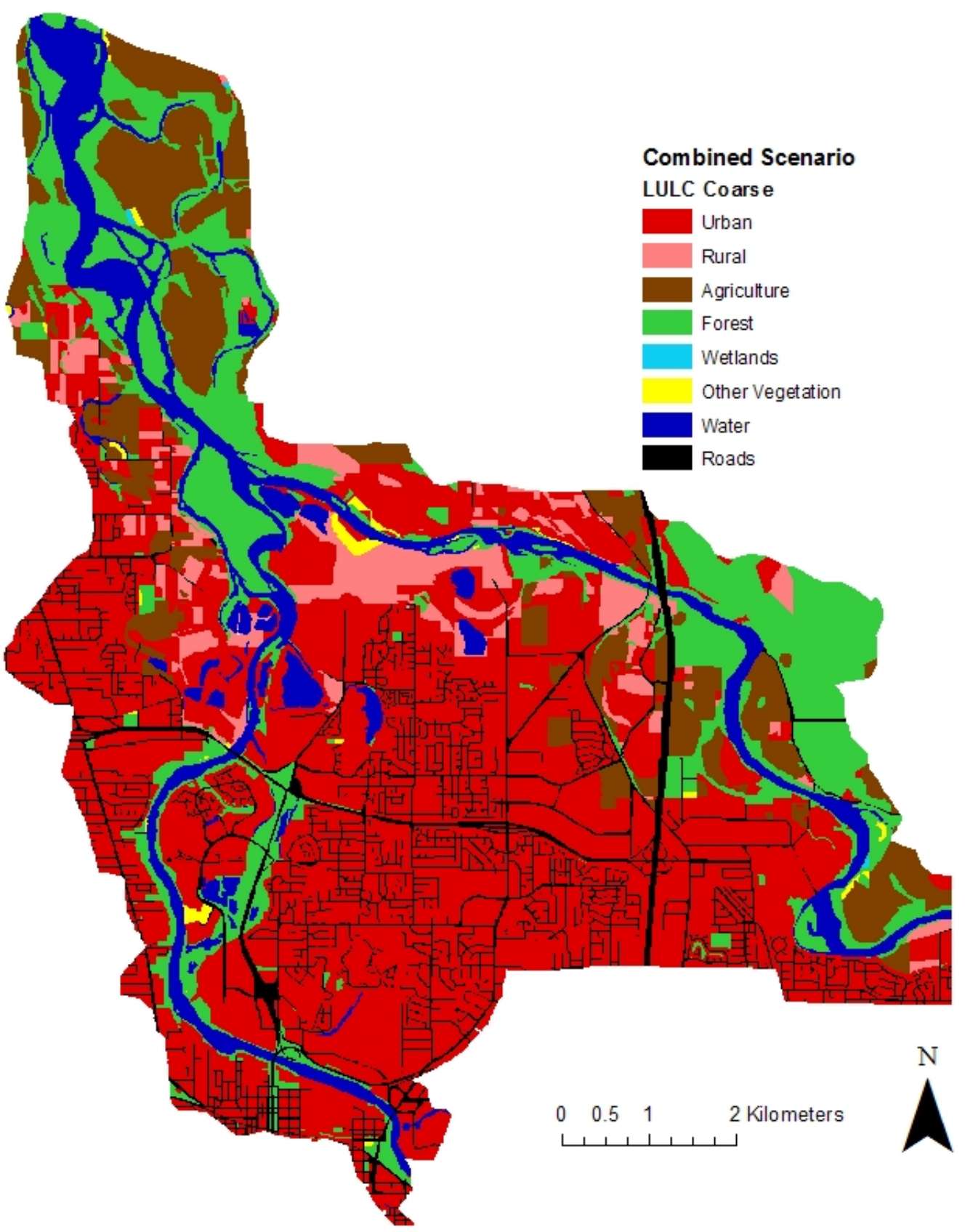


Table 5. PNW-ERC distribution of land uses between initial conditions and percent land use in year 50 for plan trend, conservation, and development scenarios.

\begin{tabular}{lccccc}
\hline \hline Scenario & Urban & Farm & Forest & Other & Total \\
\hline $\begin{array}{l}\text { Initial conditions } \\
\text { (ha) }\end{array}$ & 1898 & 1858 & 805 & 2530 & 7091 \\
$\begin{array}{l}\text { Initial conditions } \\
(\%)\end{array}$ & 26.8 & 26.2 & 11.4 & 36.3 & 100 \\
$\begin{array}{l}\text { PNW-ERC plan } \\
\text { trend 2050 (\%) }\end{array}$ & 31.5 & 24.6 & 11.2 & 35.0 & 100 \\
$\begin{array}{l}\text { PNW-ERC conser- } \\
\text { vation 2050 (\%) }\end{array}$ & 31.1 & 17.1 & 12.1 & 39.7 & 100 \\
$\begin{array}{l}\text { PNW-ERC develo- } \\
\text { pment 2050 (\%) }\end{array}$ & 33.6 & 20.0 & 11.3 & 32.1 & 100 \\
\hline
\end{tabular}

$16.0 \%$ more urban area than under initial conditions. The development scenario in which market forces were emphasized showed urban areas growing by $25.3 \%$ over initial conditions. The conservation scenario produces less land in agricultural production and more forest, as was the case with Evoland.

The PNW-ERC evaluative models show that native fish richness and fish biotic integrity improve over 1990 only in the PNW-ERC conservation scenario (Hulse et al. 2002:122). The average increase is 8\% over the plan trend 2050 scenario. The Evoland results show a similar pattern.

The magnitude of change in citizen-based futuring is less dramatic than that shown by Evoland modeling. The PNW-ERC futuring reflects what citizens thought was plausible in the late 1990s. Their views blended economic and ecological values. The larger changes indicated by the Evoland case study might not be representative of the PNWERC study because policies in the Evoland case study represented the effects of a 2004 statewide ballot measure that significantly weakened the landuse planning system in Oregon (Jaeger 2006), whereas growth management constraints input by stakeholders and citizens characterized the PNWERC. A statewide vote on a revision of the 2004 measure that restored many of the urban growth constraints passed in November 2007.
A sensitivity analysis (Appendix 1) clearly showed that the effects of differing policy sets between the conservation and development scenarios caused more variation in the results than variation in initial agent values and concluded that policy should be considered the more significant driver of the system. However, agent preferences were static throughout each simulation and, had they been able to evolve, might have been a larger source of variation in the results. The sensitivity analysis compared heterogeneous to homogeneous agent preferences and produced similar results to the work of Brown and Robinson (2006). Both studies used agents with preferences derived from social data and found that heterogeneous agents amplify the potential for landscape change compared to homogeneous agents (Brown and Robinson 2006). The Evoland approach represented the initial spatial covariance of agent preferences, whereas the approach of Brown and Robinson generated the pattern. In the case study, the agents that preferred economic over ecosystem health values were more prevalent in the critical habitat area. This is a conflict of interest situation. Policies intended for critical habitat areas possibly were ignored by agents. Thus, it may be overly optimistic to conclude that policy incentives can induce land management decisions that favor fish if landowners are oblivious to societal goals. Because the case study optimized an objective function that blends global, i.e., societal, goals and local or agent preferences, the approach may be 
more suited to exploration of land-use and landcover dynamics than to reflect realistic behavioral responses to changes in land-use policies (Waddell and Ulfarsson 2004). Because the objective function was optimized in a sequential manner over time for $50 \mathrm{yr}$ into the future, the results should not be interpreted as guidelines for land-use planning. Results obtained from a similar study with an objective balancing of the economic goals of private forest holdings and landscape-level goals for biodiversity based on current conditions could be used for land-planning guidelines (Kurttila and Pukkala 2003).

\section{CONCLUSIONS}

The modeling approach taken here addresses important issues for understanding policy effects in social-ecological systems by agent-based modeling of land use and land cover, including issues of landscape representation and scale, agent initialization from meaningful social data, integration of environmental effects, and an iterative scenario-building approach to understanding these systems. Approaching the modeling as an iterative process produced intermediate results that were less important for the predictions made than for their function as inductive steps along the path to a deeper understanding of the system. Ultimately, the process generated results that compared favorably to citizen- and stakeholder-based futuring, but that should not be considered as important as the goal of developing, first, a modeling framework that supports the accumulation of knowledge and, second, the capacity for experimentation, which is tantamount to the capacity for inductive reasoning about a complex and unknown future.

Many of the policies, landscape evaluators, and environmental and other nonagent processes developed for the study can be used for future studies with varying amounts of modification. On the other hand, our effort to specify the empirical details of the spatial distribution of agent values and to define spatial attributes that supported urban growth and residential capacity required submodels very specific to our study area. We arrived at a very costly, complex model configuration that is difficult to explain, interpret, and generalize from. Because we had already exhausted the resources available to us, we could not explore the consequences of alternative agent representations, including interactive role-playing, dynamic generation of agent preferences, mechanisms for specifying agent behavior, and other advances in the core mechanism, such as those from game theory and behavioral psychology that involve agent interactions.

Responses to this article can be read online at: http://www.ecologyandsociety.org/voll3/iss 1/art37/responses/

\section{Acknowledgments:}

We acknowledge the tremendous assistance from the subject editor of Ecology and Society and four anonymous reviewers during the development of this manuscript in the review process. The National Science Foundation Program, Biocomplexity in the Environment: Integrated Research and Education in Environmental Systems, Award No. 0120022 funded part of this research. Additional support came from Oregon State University and the University of Oregon. Support from the EXYSTENCE Network of Excellence in Complex Systems and the University of Surrey's Institute of Advanced Studies made possible our participation in the Workshop on Modeling Urban Social Dynamics, April 7-8, 2005. Comments by workshop planners and participants helped in developing this manuscript.

\section{LITERATURE CITED}

Allen, J., and K. Lu. 2003. Modeling and prediction of future urban growth in the Charleston region of South Carolina: a GIS-based integrated approach. Conservation Ecology 8(2):2. [online] URL: http://www.consecol.org/vol8/iss2/art2/.

Almeida, A. S., and A. G. Journel. 1994. Joint simulation of multiple variables with a Markov-type coregionalization model. Mathematical Geology 26 (5):565-587.

Axelrod, R. 2003. Advancing the art of simulation in the social sciences. Japanese Journal for Management Information Systems 12(2):16-22.

Baker, J., D. W. Hulse, S. V. Gregory, D. White, J. Van Sickle, P. A. Berger, D. Dole, and N. H. 
Schumaker. 2004. Alternative futures for the Willamette River Basin, Oregon. Ecological Applications 14:313-324.

Bankes, S. 2002a. Agent-based modeling: a revolution? PNAS 99(3):7199-7200.

Bankes, S. 2002b. Tools and techniques for developing policies for complex and uncertain systems. PNAS 99(3):7263-7266.

Bankes, S., R. Lempert, and S. Popper. 2002. Making computational social science effective: epistemology, methodology, and technology. Social Science Computer Review 20:377-388.

Bengston, D. N., and Y. C. Youn. 2006. Urban containment policies and the protection of natural areas: the case of Seoul's greenbelt. Ecology and Society 11(1): 3. [online] URL: http://www.ecology andsociety.org/vol11/iss1/art3/.

Benenson, I., and P. M. Torrens. 2004. Geosimulation: automata-based modeling of urban phenomena. Wiley, New York, New York, USA.

Berger, T., and P. Schreinemachers. 2006. Creating agents and landscapes for multiagent systems from random samples. Ecology and Society 11(2): 19. [online] URL: http://www.ecologyandso ciety.org/vol11/iss2/art19/.

Bernard, H. R. 2002. Research methods in anthropology: qualitative and quantitative methods. AltaMira Press, Walnut Creek, California, USA.

Bolte, J. P., D. W. Hulse, S. V. Gregory, and C. Smith. 2007. Modeling biocomplexity-actors, landscapes and alternative futures. Environmental Modelling and Software 22(5):570-579.

Brown, D. G., P. Goovaerts, A. Burnicki, and M.Y. Li. 2002. Stochastic simulation of land-cover change using geostatistics and generalized additive models. Photogrammetric Engineering \& Remote Sensing 68:1051-1061.

Brown, D. G., R. L. Riolo, D. Robinson, M. North, and W. Rand. 2005. Spatial process and data models: toward integration of agent-based models and GIS. Journal of Geographical Systems 7:1-23.

Brown, D. G., and D. T. Robinson. 2006. Effects of heterogeneity in residential preferences on an agent-based model of urban sprawl. Ecology and Society 11(1): 46. [online] URL: http://www.ecolog yandsociety.org/vol11/iss1/art46/.

Common, M., and C. Perrings. 1992. Towards an ecological economics of sustainability. Ecological Economics 6:7-34.

Daniels, M. 1999. Integrating simulation technologies with Swarm. Swarm Programming Group Technical Paper. Available online at: $\underline{\text { http:// }}$ www.swarm.org/wiki/Main Page.

Davis, F. L., and A. H. Wurth, Jr. 2003. Voting preferences and the environment in the American electorate: the discussion extended. Society and Natural Resources 16:729-740.

Deacon, R., and P. Shapiro. 1975. Private preference for collective goods revealed through voting on referenda. American Economic Review $\mathbf{6 5}$ (5):943-955.

Deutsch, C. V., and A. G. Journel. 1998. GSLIB: geostatistical software library and user's guide. Second edition. Oxford University Press, New York, New York, USA.

Dietz, T., P. C. Stern, and G. A. Guagnano. 1998. Social structural and social psychological bases on environmental concern. Environment and Behavior 30:450-471.

Dietzel, C., and K. C. Clarke. 2004. Spatial differences in multi-resolution urban automata modeling. Transactions in GIS 8(4):479-492.

Dunlap, R. E., K. Van Liere, A. G. Mertig, and R. Jones. 2000. Measuring endorsement of the new environmental paradigm: a revised NEP scale. Journal of Social Issues 56:425-442.

Evans, T. P., and H. Kelley. 2004. Multi-scale analysis of a household level agent-based model of landcover change. Journal of Environmental Management 72(1/2):57-72.

Ewert, F., M. D. A. Rounsevell, I. Reginster, M. J. Metzger, and R. Leemans. 2005. Future scenarios of European agricultural land use. I. Estimating changes in crop productivity. Agriculture, Ecosystems and Environment 108:117-135.

Farber S., R. Costanza, D. L. Childers, J. 
Erickson, K. Gross, M. Grove, C. S. Hopkinson, J. Kahn, S. Pincetl, A. Troy, P. Warren, and M. Wilson. 2006. Linking ecology and economics for ecosystem management. BioScience 56(2):117-129.

Farm Service Agency (FSA). 2006. Conservation Reserve Program: enrollment statistics and program information, 2005 Fiscal Year. Available online at: http://www.fsa.usda.gov/Internet/FSA File/fy2005. pdf.

Foley, J. A., R. DeFries, G. P. Anser, C. Barford, G. Bonan, S. R. Carpenter, F. S. Chaplin, M. T. Coe, G. C. Daily, H. K. Gibbs, J. H. Helkowski, T. Holloway, E. A. Howard, C. J. Monfreda, J. A. Patz, I. C. Prentice, N. Ramankutty, and P. K. Snyder. 2005. Global consequences of land use. Science 309:570-574.

Gelissen, J. (2007). Explaining popular support for environmental protection. Environment and Behavior 39:392-415.

Gilbert, G. N., and K. G. Troitzsch. 2005 . Simulation for the social scientist. Second edition. Open University Press, Maidenhead, New York, USA.

Graniero, P.A., and V. B. Robinson. 2006. A probe mechanism to couple spatially explicit agents and landscape models in an integrated modelling framework. International Journal of Geographical Information Science 20(9):965-990.

Gregory, S., D. Hulse, S. Payne, A. Branscomb, and L. Ashkenas. 2002. Priorities for restoration. Pages 144-145 in D. Hulse, S. Gregory, and J. Baker, editors, Willamette River $B$ asin planning atlas: trajectories of environmental and ecological change. Oregon State University Press, Corvallis, Oregon, USA.

Grimm, V., U. Berger, F. Bastiansen, S. Eliassen, V. Ginot, J. Giske, J. Goss-Custard, T. Grand, S. Heinz, G. Huse, A. Huth, J. U. Jepsen, C. Jørgensen, W. M. Mooij, B. Müller, G. Pe'er, C. Piou, S. F. Railsback, A. M. Robbins, M. M. Robbins, E. Rossmanith, N. Rüger, E. Strand, S. Souissi, R. A. Stillman, R. Vabø, U. Visser, and D. L. DeAngelis. 2006. A standard protocol for describing individual-based and agent-based models. Ecological Modelling 198:115-296.

Hascic, I. 2006. Essays on land use regulation.
Dissertation. Department of Agricultural and Resource Economics, Oregon State University, Corvallis, Oregon, USA.

Herzog, R. 2005. Agri-environment schemes as landscape experiments. Agriculture, Ecosystems and Environment 108:175-177.

Holland, J. H. 1998. Emergence. Perseus Books, Cambridge, Massachusetts, USA.

Hulse, D. W., S. V. Gregory, and J. Baker, editors. 2002. Willamette River Basin planning atlas: trajectories of environmental and ecological change. Oregon State University Press, Corvallis, Oregon, USA.

Jaeger, W. K. 2006. The effects of land-use regulations on property values. Environmental Law 36:105-130.

Janssen, M. A., and E. Ostrom. 2006. Empirically based, agent-based models. Ecology and Society 11 (2):37. [online] URL: http://www.ecologyandsociety. org/vol11/iss2/art37/.

Kahn, M. E., and J. G. Matsusaka. 1997. Demand for environmental goods: evidence from voting patterns on California initiatives. Journal of Law and Economics 40:137-173.

Karp, D. R. 2000. Values theory and research. Pages 3212-3227 in E. F. Borgatta and R. J. V. Montgomery, editors. Encyclopedia of sociology. Macmillan, New York, New York, USA.

Kauffman, J. B., R. L. Beschta, N. Otting, and D. Lytjen. 1997. An ecological perspective of riparian and stream restoration in the western United States. Fisheries 22(5):12-24.

Kolakowski, K., P. L. Machemer, J. Thomas, and R. Hamlin. 2000. Urban growth boundaries: a policy brieffor the Michigan Legislature. Urban and Regional Planning Program, Department of Geography, Michigan State University, Lansing, Michigan, USA. Available online at: http://www.ip psr.msu.edu/Publications/ARUrbanGrowthBound.pdf

Klügl, F., M. Fehler, and R. Herrler. 2004. About the role of the environment in multi-agent simulations. Pages 127-149 in Danny Weyns, H. Van Dyke Parunak, and Fabien Michel, editors. 
Environments for multi-agent systems. Lecture Notes in Computer Science. Springer, Berlin, Germany.

Kurttila, M., and T. Pukkala. 2003. Combining holding-level economic goals with spatial landscape-level goals in the planning of multiple ownership forestry. Landscape Ecology 18:529-541.

Land Trust Alliance. 2006. National land trust census. Available online at: http://www.lta.org/abo utlt/census.shtml.

Langridge, R., J. Christian-Smith, and K. A. Lohse. 2006. Access and resilience: analyzing the construction of social resilience to the threat of water scarcity. Ecology and Society 11(2):18. [online] URL: http://www.ecologyandsociety.org/vol11/ iss2/art18/

Levin, S. A. 1998. Ecosystems and the biosphere as complex adaptive systems. Ecosystems 1:431-436.

Manfredo, M. J., and A. A. Dayer. 2004. Concepts for exploring the social aspects of human-wildlife conflict in a global context. Human Dimensions of Wildlife 9:317-328.

Meleason, M.A., S. V. Gregory, and J. Bolte. 2002. Simulation of stream wood source distance for small streams in the western Cascades, Oregon. U.S Forest Service General Technical Report PSWGTR-181. Available online at: http://www.fs.fed.us/ psw/publications/documents/gtr-181/036 Meleason. pdf.

Michener, W. K., T. J. Baerwald, P. Firth, M. A. Palmer, J. L. Rosenberger, E. A. Sandlin, and H. Zimmerman. 2001. Defining and unraveling biocomplexity. BioScience 51(12):1018-1023.

Nassauer, J., and R. Corry. 2004. Using normative scenarios in landscape ecology. Journal of Landscape Ecology 19:343-356.

National Oceanic and Atmospheric Administration (NOAA) Fisheries. 2005. ESA salmon listings: salmon populations. Available online at: http://ww w.nwr.noaa.gov/ESA-Salmon-Listings/SalmonPopulations/Index.cfm.

Natural Resources Conservation Service (NRCS). 2002. 2002 Farm Bill programs. Available online at: http://www.nrcs.usda.gov/programs/farmbill/2002/ products.html.
Natural Resources Conservation Service (NRCS). 2006. FY 2004 conservation allocations to states. Available online at: http://www.nrcs.usda.gov/prog rams/2005 Allocations/2005 Allocations.html.

Osgood, C.E., G. Suci, and P. Tannenbaum. 1957. The measurement of meaning. University of Illinois Press, Urbana, Illinois, USA.

Parker D. C., S. M. Manson, M. A. Janssen, M. J. Hoffmann, and P. Deadman. 2003. Multi-agent systems for the simulation of land-use and landcover change: a review. Annals of the Association of American Geographers 93:314-337.

Perrings, C. 2006. Resilience and sustainable development. Environment and Development Economics 11:417-427.

Pierce, J. T., and O. J. Furuseth. 1982. Farmland protection planning in British Columbia. GeoJournal 6(6):555-560.

Remy, N. 2001. GsTL: the geostatistical template library in $\mathrm{C}++$. Thesis. Department of Petroleum Engineering, Stanford University, Palo Alto, California, USA.

Ricketts, T., and M. Imhoff. 2003. Biodiversity, urban areas, and agriculture: locating priority ecoregions for conservation. Conservation Ecology 8(2): 1. [online] URL: http://www.consecol.org/vol8/ iss2/art1.

Rokeach, M. 1973. The nature of human values. Free Press, New York, New York, USA.

Rounsevell, M. D. A., F. Ewert, I. Reginster, R. Leemans, and T. R. Carter. 2005. Future scenarios of European agricultural land use. II. Projecting changes in cropland and grassland. Agriculture, Ecosystems and Environment 108:117-135.

Sabatier, P. A., W. D. Leach, M. Lubell, and N. W. Pelkey. 2004. Theoretical frameworks explaining partnership success. Pages 173-199 in P. A. Sabatier, W. Focht, M. Lubell, Z. Trachtenberg, A. Vedlitz, and M. Matlock, editors. Swimming upstream: collaborative approaches to watershed management. MIT Press, Cambridge, Massachusetts, USA.

Salka, W. M. 2003. Determinants of countywide voting behavior on environmental ballot measures: 
1990-2000. Rural Sociology 68:253-277.

SAS Institute. 2004. SAS/STAT. SAS Institute, Cary, North Carolina, USA.

Schelling, T. C. 1971. Dynamic models of segregation. Journal of Mathematical Sociology 1:143-186.

Schmitzberger, I., T. Wrbka, B. Steurer, G. Aschenbrenner, J. Peterseil, and H. G. Zechmeister. 2005. How farming styles influence biodiversity maintenance in Austrian agricultural landscapes. Agriculture, Ecosystems and Environment 108:274-290.

Steel, B. S., R. L.Clinton, and N. P. Lovrich. 2003. Environmental politics and policy: a comparative approach. McGraw-Hill, Boston, Massachusetts, USA.

Tilman, D. 2000. Causes, consequences and ethics of biodiversity. Nature 405:208-211.

Tilman, D., K. G. Cassman, P. A. Matson, R. Naylor, and S. Polasky. 2002. Agricultural sustainability and intensive production practices. Nature 418:671-677.

U.S. Bureau of the Census. 2005. Subjects index. Available online at: http://factfinder.census.gov/servlet/ GCTTable? bm=y\&-context=gct\&-ds name $=$ DEC 2000 SF1 U\&-CONTEXT $=$ gct\&-mt name= DEC 2000 SF1 U GCTPH1 ST4\&-tree id=4001\&redoLog $=$ true $\&$ - caller $=$ geoselect $\&$-geo $\mathrm{id}=05000$ US41039\&-format $=$ CO-2\&- lang=en.

Van Liere, K., and R. E. Dunlap. 1980. The social bases of environmental concern: a review of hypotheses, explanations, and empirical evidence. Public Opinion Quarterly 44:43-59.

Van Meijl, H., T. Van Rheenen, A. Tabeau, and B. Eickhout. 2006. The impact of different policy environments on agricultural land use in Europe. Agriculture, Ecosystems and Environment 114 (1):21-38.

Van Sickle, J. V., J. Baker, A. Herlihy, P. Bayley, S. Gregory, P. Haggerty, L. Ashkenas, and J. Li. 2004. Projecting the biological condition of streams under alternative scenarios of human land use. Ecological Applications 14(2):368-380.
Vaske, J. J., M. P. Donnelly, D. R. Williams, and S. Jonker. 2001. Demographic influences on environmental value orientations and normative beliefs about national forest management. Society and Natural Resources 14:761-776.

Veldkamp, A., and P. H. Verburg. 2004. Modeling land use change and environmental impact. Journal of Environmental Management 72:1-3.

Vossler, C. A., and J. Kerkvliet. 2003. A criterion validity test of the contingent valuation method: comparing hypothetical and actual voting behavior for a public referendum. Journal of Environmental Economics and Management 45:631-649.

Vossler, C. A., J. Kerkvliet, S., Polasky, and O. Gainutdinova. 2003. Externally validating contingent valuation: an open-space survey and referendum in Corvallis, Oregon. Journal of Economic Behavior and Organization 51:261-277.

Waddell, P., and G. F. Ulfarsson. 2004 Introduction to urban simulation: design and development of operational models. Pages 203-236 in P. Stopher, K Button, K. Haynes, and D. Hensher, editors. Handbook of transport. Volume 5. Transport geography and spatial systems. Pergamon Press, New York, New York, USA.

Wolfram, S. 1983. Cellular automata. Los Alamos Science 9:2-21. 
Appendix 1. Agent initialization and sensitivity to agent initialization. (pdf)

\section{Please click here to download file 'appendix1.pdf'.}


Appendix 2. GIS attributes and sources (pdf)

Please click here to download file 'appendix2.pdf'. 
Appendix 3. Policy Summaries (pdf)

Please click here to download file 'appendix3.pdf'. 
Appendix 4. Parameters (pdf)

Please click here to download file 'appendix4.pdf'. 
Appendix 5. Vegetative succession submodel (pdf)

Please click here to download file 'appendix5.pdf'. 
Appendix 6. Population and residential capacity submodel (pdf)

Please click here to download file 'appendix6.pdf'. 
Appendix 7. Economics submodel (pdf)

Please click here to download file 'appendix7.pdf'. 
Appendix 8. Ecosystem health submodel (pdf)

Please click here to download file 'appendix8.pdf'. 